\title{
NACIMIENTOS FUERA DEL MATRIMONIO EN LA HISTORIA DE CHILE: ALGUNOS HECHOS ESTILIZADOS
}

\author{
José Díaz \\ Pontificia Universidad Católica de Chile \\ Francisco A. Gallego \\ Pontificia Universidad Católica de Chile \\ Jeanne Lafortune \\ Pontificia Universidad Católica de Chile
}

\begin{abstract}
RESUmen: Este trabajo identifica y examina una serie de hechos estilizados en la evolución histórica de la tasa de ilegitimidad en Chile, considerando datos agregados desde 1848 hasta el presente, así como datos a nivel departamental para el período 1862-1948. Los resultados más sustantivos apuntan a que las tasas de ilegitimidad y de matrimonios son fenómenos que cambian frente a transformaciones en la estructura económica y social existente y a los incentivos que
\end{abstract}

José DíAz. Profesor del Instituto de Economía e investigador del Economic History and Cliometrics Laboratory (EH Clio Lab) de la Pontificia Universidad Católica de Chile (UC). Email: jdiazb@uc.cl.

Francisco A. Gallego. Profesor del Instituto de Economía e investigador del EH Clio Lab de la UC. Email: fgallego@uc.cl.

Jeanne Lafortune. Profesor del Instituto de Economía e investigador del EH Clio Lab de la UC. Email: jlafortune@uc.cl.

Los autores quieren señalar que este artículo se ha beneficiado de los comentarios de los árbitros anónimos de Estudios Públicos. Dicen también: "Agradecemos a Dominique Araya y Francisca San Juan por su excelente asistencia de investigación y a Conicyt / Programa de Investigación Asociativa (Project SOC 1102) por el apoyo financiero. Mantenemos el monopolio de los errores y de las omisiones". 
ello genera en el comportamiento de los agentes. En particular, los resultados sugieren que el fuerte aumento de la tasa de ilegitimidad entre 1880 y 1920 probablemente va asociado a un intenso proceso de urbanización y de movimientos desde el campo (y de la agricultura) a la ciudad. Este gran aumento en la tasa de ilegitimidad del período mencionado no se compensa con los efectos de ingreso hasta la década de 1920. La contracara de este fenómeno es la tasa de matrimonios por población, en la que encontramos que existe una correlación robusta con la razón de hombres a mujeres y con medidas de desarrollo económico, en que a más desarrollo hay más posibilidades de formalizar la relación de pareja en un matrimonio.

Palabras Clave: matrimonio, hijos fuera del matrimonio, nacimientos ilegítimos, análisis económico de la familia.

RECIBIDO: noviembre 2015; ACEPTADO: enero 2016.

Clasificación JEL: D10, J12, J13, N30.

\section{OUT-OF-WEDLOCK BIRTHS IN CHILE: SOME STYLIZED FACTS}

ABSTRACT: This paper presents a series of stylized facts about the historical evolution of the rate of illegitimacy in Chile, looking both at aggregate data from 1848 to the present and at department-level data for the 1862-1948 period. The main results suggest that the rate of illegitimacy and marriage are phenomena that change depending on the economic and social structure and the incentives present in different periods rather than being predetermined structural and historical situations. In particular, our results suggest that the sharp increase in the rate of illegitimacy in the period between 1880 and 1920 probably is correlated with urbanization and migration to cities (and agriculture from other sectors). This is not compensated by significant income effects until the early 1920s. In parallel, the ratio of marriages to the total population is also strongly correlated with the sex-ratio and with proxies of economic activity.

KEYWORDS: marriage, out-of-wedlock births, illegitimate children, family economics.

RECEIVED: November 2015; ACCEPTED: January 2016.

JEL Classification: D10, J12, J13, N30.

\section{INTRODUCCIÓN}

E xiste una amplia discusión de política pública en el mundo y en Chile sobre las causas y las consecuencias del aumento de los nacimientos fuera del matrimonio, a veces referidos en la literatura como ilegitimidad. Sin embargo, cuando se mira la historia de Chile (y de otros 
países) parece que la ilegitimidad no es un fenómeno reciente, lo que sugiere que entender sus mecanismos históricos nos puede ayudar a entender la realidad de hoy. De hecho, el tema de los nacimientos fuera del matrimonio es parte tanto de los estudios internacionales sobre historia de la familia (Burguière et al. 1988; Wall et al. 2001; Kertzer y Barbagli 2001; 2002 y 2003), como de la historiografía chilena (Montecino 2010; Rojas 2010; Salazar 1990 y 2007). En este último caso se han explorado tanto explicaciones sobre la evolución de la tasa de ilegitimidad como acerca de las consecuencias económicas y sociales de la misma.

Este trabajo toma una perspectiva descriptiva y realiza dos aportes. En primer lugar, identifica algunos hechos estilizados respecto de la evolución de la tasa de niños nacidos fuera del matrimonio desde mediados del siglo XIX hasta el presente. ${ }^{1}$ En segundo lugar, presenta el primer estudio econométrico detallado de las variables correlacionadas con esta tasa a nivel de departamentos de Chile desde 1862 hasta 1948. Este período corresponde justamente a una etapa de la historia muy discutida en la historiografía de Chile respecto de temas como ilegitimidad y "huachismo" (Montecino 2010; Salazar 1990 y 2007) y durante la cual además se observa un importante aumento en la tasa de ilegitimidad (entre comienzos de la década de los 1880 y fines de los 1910) para luego comenzar a descender a valores más bajos (desde los 1920 hasta los 1960). En orden a entender mejor este fenómeno, complementamos el análisis con una mirada a la tasa de matrimonios en la misma época.

Las tendencias agregadas sugieren que la tasa de niñas y niños nacidos fuera del matrimonio sigue un patrón oscilante en el tiempo: un período inicial desde 1848 (primer año en que tenemos datos) y comienzos de los 1880, en que se mantiene una cierta estabilidad de esta tasa, para luego aumentar fuertemente hasta fines de la década de los 1920, para después descender hasta un mínimo histórico en torno a 1960 y luego comenzar un período de aumento secular que aún no termina y que supera con creces el máximo histórico previo. Ciertamente, la contracara de este fenómeno es la tasa de matrimonios por población, que presenta el patrón opuesto: justamente los períodos de mayor aumento del ratio de niños nacidos fuera del matrimonio respecto del total corresponden a períodos en que los matrimonios bajan fuertemente.

${ }^{1}$ En este artículo, los términos "hijo ilegítimo" y "nacido fuera del matrimonio" se emplean como equivalentes. 
Cuando se miran los datos en perspectiva comparada se observa que el aumento secular posterior a 1960 también se presenta en países para los cuales tenemos series de datos comparables con las nuestras, como Estados Unidos y el Reino Unido. Al mismo tiempo, los datos para Chile de todo el período previo a 1970 hablan de una situación en la que se observan tasas de ilegitimidad mucho más altas que en estos países. Por otro lado, la información histórica existente sugiere que un porcentaje de los niños nacidos fuera el matrimonio, en el período de aumento de este ratio entre 1880 y 1920, fueron luego "legitimizados". Así, los datos disponibles para Chile muestran que entre 1933 y 1948 aproximadamente el 25 por ciento de los matrimonios nuevos legitimizaban hijos nacidos previamente. Lamentablemente, no tenemos datos disponibles sobre el total de niños legitimizados salvo para 1933 y 1934, cuando cada nuevo matrimonio que legitimiza hijos lo hace a una tasa de algo más de 2 niños por matrimonio. Esto implica que en esos dos años el porcentaje de niños legitimizados respecto del total de niños ilegítimos es de 37 por ciento en promedio, lo que lleva a que la tasa de ilegitimidad caiga de cerca de 30 por ciento a un número cercano al 20 por ciento. Esto es consistente con el detallado trabajo demográfico de McCaa (1983) para Petorca, quien señala que "muchos niños nacieron en concubinatos que después condujeron a matrimonio", por lo que "los niveles reales de ilegitimidad (bastardy) eran 25-40 por ciento menores que lo indicado en las cifras convencionales" (McCaa 1983, 43-46).

En orden a analizar la información e interpretar los resultados tomamos una perspectiva múltiple: recogemos hipótesis planteadas en la historiografía nacional como también en estudios internacionales sobre el tema, y agregamos las hipótesis planteadas por la literatura económica moderna sobre temas de matrimonio, natalidad y familia. Nos enfocamos en una serie de hipótesis específicas: el rol de la desigualdad entre los latifundistas y los inquilinos en el campo; el rol de los costos del matrimonio; y el rol del poder de negociación entre hombres y mujeres. Vamos a aproximar la primera hipótesis por el papel de la agricultura y la prevalencia de zonas urbanas o rurales. Para evaluar la segunda hipótesis no tenemos variación en el costo del matrimonio a través del tiempo, pero usaremos la variación en la riqueza local (medida por urbanización y crecimiento en la población), lo que permitiría a las parejas poder pagar más fácilmente los costos fijos (y constantes 
en toda la República) del matrimonio. Finalmente, la última conjetura se mide usando la razón de géneros, tradicionalmente empleada para argumentar que, cuando hay más hombres que mujeres, los varones tienen una menor capacidad de negociación ante sus parejas. Además, consideraremos la importancia de los puertos en la costa, que pueden influir en este último argumento si se genera una población "flotante" de hombres en la zona.

La novedad del análisis viene en parte de la construcción de una base de datos a nivel de departamentos que cubre desde mediados del siglo XIX hasta la mitad del siglo XX. Se ha procurado que las zonas geográficas sean uniformes durante el periodo e incluimos todos los departamentos y regiones de Chile (para las regiones que se incluyen en el país, se incorporan los departamentos al momento en que se consideran en el Censo). La ventaja de usar este tipo de datos es que podemos controlar por varios elementos que son comunes a todos los departamentos (cambios en política nacional como la asignación familiar en 1937, shocks económicos al nivel nacional) o características específicas de zonas geográficas constantes a través del tiempo (clima, topografía u otro). Luego, nuestros resultados indican cómo cambios en las condiciones de una zona geográfica influyen en decisiones de fertilidad y matrimonio, limpiando nuestro estimador de otras consideraciones. Por ejemplo, para explorar la hipótesis de que la ilegitimidad puede depender de la razón de mujeres por hombres en una zona, uno podría abrigar el temor de que la razón de géneros y la tasa de ilegitimidad son ambas determinadas por factores culturales de cada región. Nuestra configuración de datos permite eliminar estos factores si son constantes a través del tiempo y así asumir que la correlación estimada está limpia de estos problemas. No obstante, no podemos evaluar tendencias de largo plazo dado que comparamos información de departamentos observada en un momento. Por ello empezamos con el análisis descriptivo de los datos a nivel nacional.

El ejercicio empírico para el período 1862-1948 con datos departamentales ayuda a entender la variación existente dentro del país y sus causas, y de ese modo facilita la interpretación de los patrones que observamos. Nuestros resultados implican, por un lado, que la tasa de ilegitimidad aumenta fuertemente en períodos que se asocian con incrementos de la urbanización de los departamentos y cae fuertemente 
en períodos en que crece la población departamental (lo que se asocia a situaciones de expansión económica). Este punto es consistente con la discusión de Rojas (2010). Por otro lado, también observamos que la tasa de ilegitimidad es mayor en departamentos con puertos con comercio activo (denotando la existencia de una población flotante importante) y parece disminuir en momentos en que la producción agrícola aumenta. Este último resultado contrasta con parte de la argumentación histórica que plantea que el "huachismo" sería un fenómeno inherentemente asociado a la agricultura (Salazar 1990 y 2007). En un sentido más profundo nuestros resultados sugieren que la ilegitimidad es un fenómeno que responde a cambios en las situaciones económicas y sociales más que a factores estructurales inmutables en el tiempo.

Ciertamente, la contracara de la ilegitimidad corresponde a la tasa de matrimonios y por ello también desarrollamos un estudio empírico complementario a nivel departamental para entender los determinantes de la tasa de matrimonios. En este caso, observamos que existe una correlación robusta con la razón de hombres a mujeres (lo que es consistente con la literatura moderna que enfatiza el rol del poder de negociación en la decisión de matrimonio) y con medidas de desarrollo económico, en que a más desarrollo hay más posibilidades de formalizar la relación de pareja en un matrimonio. Estos resultados complementan los obtenidos sobre ilegitimidad.

El resto de este trabajo se organiza de la siguiente manera. La sección 2 presenta una discusión histórica para Chile. La sección 3 desarrolla una breve revisión de la teoría económica moderna sobre familia y las hipótesis que estudiaremos empíricamente. La sección 4 presenta una descripción de los datos usados en este estudio. La sección 5 entrega los datos agregados para Chile y una comparación internacional. La sección 6 expone los análisis que realizamos a nivel departamental para el período 1862-1948. Y en la sección 7 se realiza una breve conclusión.

\section{LA ILEGITIMIDAD EN LA INVESTIGACIÓN HISTÓRICA}

Existen indicios de que en el siglo XVIII el porcentaje de hijos ilegítimos experimentó un aumento en diferentes países de Europa y en Hispanoamérica (Hartley 1975). La investigación histórica internacional ha procurado establecer la dimensión del fenómeno a través de aná- 
lisis demográficos, y ha explorado hipótesis sobre causas y efectos de esta tendencia. Por ejemplo, tras examinar la evolución de la ilegitimidad en Inglaterra y Gales, Laslett y Wall (1972) y Laslett y Oosterveen (1973) sugieren como determinante del fenómeno la postergación en la decisión de contraer matrimonio (hipótesis discutida por Schelleckens 1995 y Ermisch 2008).

Los estudios de la evolución de la ilegitimidad en Chile comparten motivaciones similares a las de la investigación internacional, aunque el énfasis parece concentrarse menos en la cuantificación y más en el examen de sus causas y efectos. Hablando en general, las investigaciones que abordan el tema suelen enfatizar dos elementos. El primero de ellos es la discusión y cuestionamiento al ordenamiento jurídico que consagraba un estatus de desprotección a un grupo de la sociedad. ${ }^{2}$ El segundo elemento es la inquietud sobre la situación de los niños ilegítimos y los efectos de esta condición sobre su calidad de vida. La condición de ilegitimidad estaría asociada a situaciones de abandono y miseria, afectando así las posibilidades de desarrollo personal.

Una primera forma de acercamiento al tema proviene del análisis de la evolución de los mecanismos de configuración y de las características de la estructura familiar en Chile. Aquí caben tanto los estudios históricos como los de corte jurídico sobre la familia, y en este contexto la ilegitimidad es visualizada como un problema de precarización y marginalidad causada por el marco institucional vigente. ${ }^{3}$

Este tipo de investigaciones plantea que la familia en el Chile hispano es de tipo nuclear con escaso énfasis en los afectos y formalizaciones (Cavieres y Salinas 1991; Goicovic 2006; Salinas 2004 y 2005a). En el siglo XVIII, la formación de la familia y el desarrollo de la vida familiar seguían una serie de tradiciones propias de un orden estamental (Muñoz 2005; Retamal 2005). La condición de ilegitimidad parece ha-

${ }^{2}$ El apéndice presenta una breve revisión del ordenamiento jurídico que gobernaba la situación de los niños nacidos fuera del matrimonio. Esto es importante para entender y contextualizar diferentes puntos que se mencionan más adelante.

${ }^{3}$ En Hispanoamérica, la ilegitimidad en el siglo XVIII implicó la prohibición expresa del acceso a ciertos cargos públicos, al ejercicio de algunas profesiones e incluso reducía la posibilidad de formalizar matrimonios (Twinam 1999, 47). Honor, legitimidad y limpieza de sangre estaban reglados e interconectados. La única solución era la compra de un decreto oficial de legitimación llamado "cédula de gracias al sacar", un recurso costoso. 
ber sido común en los diferentes grupos étnicos según el examen demográfico de Malloa, San Fernando, realizado por Muñoz (1990).

El paso al siglo XIX implicó que el pensamiento liberal procurase hacer de la familia constituida legalmente una especie de instrumento civilizador (Salinas 2005b y 2010; Pereira 2007). En este contexto, Milanich (2009) muestra cómo el Código Civil vigente desde 1857 derivó en una serie de perjuicios para los niños clasificados como ilegítimos. Un efecto de esta norma sería el abandono regular de niños en hogares especiales (casa de expósitos) a la espera de una adopción o de una oportunidad de trabajo en algún hogar. La autora mencionada postula, incluso, la existencia de una especie de servidumbre tutelar para estos niños.

El vínculo entre ilegitimidad y abandono está también presente, por ejemplo, en la investigación de Delgado (1986 y 2001) así como en la de Salinas y Delgado (1990). Estos trabajos indagan en las características de los niños entregados a la Casa de Expósitos (huérfanos) en Santiago desde su creación en 1761, los que eran en su mayoría ilegítimos. Las condiciones de vida en dicha Casa no eran adecuadas a pesar de los esfuerzos de las autoridades, lo que se tradujo en una considerable mortalidad. En la práctica, además, la Casa de Expósitos se convirtió en un refugio para parturientas pobres (Zárate 2007, 377 y ss.).

No obstante, cabe señalar que el carácter de expósito, es decir de "padres no conocidos", no necesariamente se traducía en abandono definitivo (Twinan 1999, cap. 5). Milanich (2009) documenta que en algunos casos la madre se ofrecía como nodriza del hijo abandonado o intentaba recuperarlo tiempo después, un procedimiento que se hizo más restringido a medida que avanzó el siglo XIX.

Una segunda aproximación historiográfica pone énfasis en el impacto social de la ilegitimidad. En este enfoque, la condición de ilegitimidad es un reflejo de características de la sociedad chilena y, a su vez, constituye un indicador de la precariedad y la pobreza.

Una versión de esta aproximación deriva de la antropología cultural y es propuesta por Montecino (2010). En este enfoque, la alta tasa de ilegitimidad en Chile refleja y define el ser chileno. En palabras de esta autora, la ilegitimidad "jugó un papel esencial en la formación de nuestra sociedad, y creemos que sus implicancias no sólo pueden analizarse desde un correlato sexual y cultural sino también social" (Monte- 
cino 2010, 50). Aunque la legislación decimonónica habría condenado las relaciones que dan origen a hijos ilegítimos, esta práctica no se habría atenuado. El resultado habría sido una estructura social fundada en la simulación del orden y la normalidad, mientras paralelamente se forjaba un "horizonte de mestizos" y abandonados, fuente de origen de los trabajadores migrantes.

La ilegitimidad sería propiciada por la proliferación de relaciones de amancebamiento y de adulterio. Esto, a su vez, respondería a la estratificación social colonial, a la composición demográfica (abundancia relativa de mujeres respecto a hombres) y a trabas legales, específicamente, el costo del matrimonio. Este último punto fue señalado en 1836 por José Javier de Guzmán, quien, preocupado por la "despoblación de la República", planteó que "es de absoluta necesidad proporcionar a los miserables que hai en nuestro país otros medios más eficaces, así para su subsistencia, como para que sin obstáculo alguno puedan contraer matrimonio, y puedan mantener sus familias con comodidad. (...) No teniendo un infeliz cómo subsistir individualmente, carece también de aquellos medios que le proporciona tomar el estado de matrimonio, y se halla sin resolución para casarse. ¡Ah! ¿Cuántos dejan de hacerlo por la triste reflexión de que no tienen cómo mantener la mujer, y a los hijos que resulten de su matrimonio?" (De Guzmán 2011, 568-569).

Una segunda versión de esta aproximación procede de la historia social y de la historia de la infancia, representadas en los escritos de Gabriel Salazar (1990 y 2007), Ponce de León et al. (2006) y Jorge Rojas (2010). Para Salazar, la ilegitimidad es resultado de la precariedad laboral que impedía la generación de un ingreso regular que permitiera la mantención de una familia. A su vez, la necesidad de subsistencia de estos niños "huachos" habría propiciado en ellos la formación de una "identidad popular", siendo "el origen histórico del machismo popular y la conciencia proletaria en Chile" (Salazar 1990, 67). En un artículo posterior, Salazar (2011) parece considerar a la tasa de ilegitimidad ("tasa de niños huachos" según sus palabras) como un indicador de pobreza o negativo per se.

Sin el énfasis identitario de Salazar, Ponce de León et al. (2006) y Rojas (2010) destacan la precariedad en las condiciones específicas de vida de los niños ilegítimos. Por ejemplo, se cita a C. E. Bladh, un 
viajero que visitó Chile en la década de 1820, que describe lo extendida que era la convivencia no matrimonial: "Los huasos que, según ya se ha dicho, carecen de un hogar estable, y siempre viven errantes, no están dispuestos a casarse, y pocos matrimonios se realizan entre las gentes de la clase baja. Otra causa de esto es la alta contribución que cobra el clero por la ceremonia religiosa de las bodas, pues el cura bendice el matrimonio por paga, y se dice que los derechos mínimos son de ocho pesos. La consecuencia de esto es que la mayoría del pueblo hace vida marital sin pasar por el matrimonio, y que se cambian esposas a su gusto. La inmoralidad en este respecto también ha aumentado a tal grado que en los campos, no solamente entre los huasos, sino también entre los propietarios y dueños de pequeñas fincas, no provoca crítica alguna el que una dama no casada viva con un hombre" (Bladh 1951, 179-180, cit. por Rojas 2010, 73).

Apoyándose en una serie de cifras a nivel nacional recopiladas desde el Anuario estadístico, Rojas (2010) postula que el incremento en la ilegitimidad desde 1880 sería resultado del cambio en los patrones morales y de la creciente urbanización, fenómenos que debilitarían la estructura familiar campesina. Sólo en el siglo XX las autoridades iniciarían un proceso de auxilio de los menores abandonados a través de la Ley de Protección a la Infancia Desvalida (1912), que postuló la intervención del Estado en la declaración de abandono de niños (Rojas 2010, 210 y ss.).

Resulta interesante señalar que parte de las impresiones presentadas sobre la ilegitimidad y su evolución se apoya referenciando a dos investigaciones hechas sobre regiones específicas: la de McCaa (1983) sobre el valle de Petorca entre 1840 y 1976, y la de Mellafe y Salinas (1987) sobre La Ligua entre 1700 y 1850. Ambos estudios revisan registros locales y sistematizan información sobre el perfil demográfico de sus áreas de estudio sin postular la representatividad de sus resultados. Ambos estudios coinciden en señalar como causas de la ilegitimidad a la miseria económica y a la promiscuidad, pero McCaa (1983, 43-46) agrega "que muchos niños nacieron en concubinatos que después condujeron a matrimonio", por lo que "los niveles reales de ilegitimidad (bastardy) eran 25-40 por ciento menores que lo indicado en las cifras convencionales". 
En resumen, el problema de la ilegitimidad ha sido explorado históricamente desde diversos enfoques y reconociendo causas y efectos variados. Para comprender cómo actúan las causas de la ilegitimidad tradicionalmente identificadas por la investigación histórica puede resultar útil ponerlas en contexto.

El carácter de ilegítimo de un niño surgía de la falta de vínculo matrimonial entre los padres. Sin embargo, dicha inexistencia podía ser ocasionada por circunstancias temporales: los padres regularizarían posteriormente su relación y de esa manera modificarían el estatus de filiación del hijo. Esto significa que los registros de ilegitimidad no son definitivos tras la inscripción del nacimiento.

Que el vínculo matrimonial no se produjera puede responder a dos situaciones. La primera de ellas es que el vínculo fuese imposible debido a la naturaleza de la relación entre los padres: es el caso de las relaciones adúlteras y sacrílegas. Acá caben aquellas explicaciones que enfatizan problemas de moralidad, pero aun así era posible modificar el estatus de filiación si existía voluntad de los padres (Milanich 2003).

La segunda situación que hace que el matrimonio no se produzca es la oposición de uno de los padres o el acuerdo mutuo basado en la presencia de algún obstáculo. En el primer caso tenemos el problema de abandono paterno o materno, y acá puede caber el argumento de la falta de compromiso motivado por carencias económicas o por alguna forma de abuso. Es conocido el argumento del aprovechamiento patronal en el mundo rural (Salazar 1990 y Montecino 2010), lo que sugiere una mayor ilegitimidad en el campo respecto a las ciudades.

En el segundo caso mencionado, estamos en presencia de una posible relación estable no formalizada (amancebamiento), donde un argumento explicativo tentativo es el costo del matrimonio. No obstante, McCaa $(1983,53)$ señala que la instauración del Registro Civil significó una reducción considerable en dicho costo sin que se aprecie un aumento en la tasa de matrimonios.

La investigación histórica ha puesto también énfasis en denunciar los efectos de la condición de ilegitimidad (Valdés 2004), ello en el marco de una preocupación por el bienestar de los niños, la crítica por su situación jurídica y socioeconómica, y su relevancia como potenciales actores sociales y políticos. 


\section{TEORÍA ECONÓMICA MODERNA: HIPÓTESIS Y RESULTADOS}

Para configurar nuestro análisis empírico, en esta sección se exponen algunos resultados de la teoría económica moderna, que intentan explicar los determinantes de la tasa de niños nacidos fuera del matrimonio, así como de la tasa de matrimonios. Básicamente, la teoría económica moderna aplicada al tema supone que la tasa de ilegitimidad responde, al menos parcialmente, a los incentivos que enfrentan los adultos y al poder de negociación relativo de hombres y mujeres (ver, por ejemplo, Neal 2004 y Akerlof et al. 1996 para referencias de esta literatura).

Una serie de trabajos argumenta que la falta de hombres (medida a través de la razón de hombres a mujeres) pone a las mujeres en una posición de negociación débil, que tiende a influenciar tanto la tasa de matrimonios como el porcentaje de niños que nacen fuera de los mismos. En este sentido, Willis (1999) expone un modelo teórico y Bethmann y Kvasnicka (2013) presentan evidencia para Alemania usando shocks asociados a la Segunda Guerra Mundial. En un ejercicio análogo, Brainerd (2007) encuentra evidencia en esta línea para Rusia durante la Segunda Guerra Mundial. De hecho, es interesante notar cómo estos antecedentes son consistentes con la argumentación presentada por Johnson (1978, 187 y ss.), Ponce de León et al. (2006) y Montecino (2010) para el caso de Chile. Es por esta razón que en los ejercicios empíricos que presentamos en este trabajo vamos a incorporar la razón de género como uno de los determinantes en nuestro análisis empírico.

Una hipótesis complementaria se relaciona con la "calidad" de los hombres existentes. Básicamente la idea se relaciona con los incentivos que tienen las mujeres a dar derechos de paternidad a los hombres vía matrimonio. Edlund (2013) argumenta que las mujeres dan los derechos de paternidad a los hombres vía matrimonio solamente si les conviene hacerlo. Entonces, para que una mujer quiera casarse para tener hijos es necesario que este hombre aporte más que el costo que implica para la mujer "perder" derechos respecto de los niños. Varios otros estudios argumentan que las mujeres afro-americanas en Estados Unidos tienen tasas muy altas de fertilidad extramarital porque los hombres afroamericanos en este país tienen tan poca probabilidad de éxito en el mercado laboral que los llevaría a convertirse más en un peso que en un aporte a la familia (Wilson 1987). Vamos a incorporar esta conjetura usando la importancia de los grandes sectores económicos en la economía regio- 
nal, y observando los puertos que podrían traer a hombres que no van a quedarse en el largo plazo.

En términos de la tasa de matrimonios y su correlación con la actividad económica, diferentes trabajos encuentran que ambas variables se correlacionan de modo positivo y significativo. El trabajo más reciente es el de Schaller (2013), que encuentra que las tasas de matrimonios son pro cíclicas, es decir, que aumentan más fuertemente cuando la actividad económica se expande. Esta relación es consistente con resultados históricos que encuentran que tanto las decisiones de matrimonio como las de divorcio son pro cíclicas usando datos de series de tiempo (Ogburn y Thomas 1922; Strouffer y Spencer 1936; Kirk 1960) y con otros trabajos recientes que emplean datos microeconómicos (Gutiérrez-Domenech 2008 para España; Kondo 2012 para Estados Unidos).

Más recientemente, el trabajo de Iyigun y Lafortune (2015) argumenta que hay un costo fijo a pagar para poder establecer un hogar y casarse. Si las conductas sexuales no cambian pero hay restricciones de riqueza para casarse, entonces, se anticiparía que lugares que son más pobres o con actividad económica más restringida tendrían que atrasar el matrimonio y, por tanto, tener más hijos fuera del matrimonio. En consecuencia, la tasa de matrimonios es más alta en momentos en que la restricción presupuestaria se relaja, lo que también es consistente con un impacto de la actividad económica en la decisión de contraer matrimonio. Vamos a medir el desarrollo económico local usando la tasa de urbanización (que acompaña en general, durante este periodo, el crecimiento económico local) y el crecimiento de la población (que se ha usado en varios estudios como proxy de desarrollo económico local).

La hipótesis mencionada se relaciona con el potencial efecto que tiene la actividad económica tanto en la tasa de niños nacidos fuera del matrimonio como en el porcentaje de matrimonios que es mencionado en los trabajos de Salazar (1990 y 2007), además de relacionarse con la literatura que enfatiza que parte del fenómeno de ilegitimidad se explica por la pobreza de la población. Por ello, en nuestros análisis empíricos estudiaremos la correlación de las variables de interés con diferentes medidas de actividad económica de las regiones del país, en particular de especialización sectorial dada la importancia de la agricultura en las tesis de Salazar (1990) y Montecino (2010).

Un corolario obvio de esta hipótesis es que en momentos de mayor actividad económica la ilegitimidad debería bajar y hacerse más 
intensa la "legitimización" de hijos en los matrimonios. Este punto ha sido mencionado ya por la literatura historiográfica para Chile (McCaa 1983). Aunque nuestros datos no nos permitirán estudiar en detalle esta última hipótesis, ya que tenemos información sólo para algunos años, los registros disponibles implican que un porcentaje importante de los niños nacidos fuera del matrimonio son "legitimizados" posteriormente, lo que sugiere que una parte de los niños nacidos fuera del matrimonio corresponden a una situación temporal que puede estar relacionada con la situación económica.

\section{CONSTRUCCIÓN DE DATOS}

Para este trabajo se elaboraron dos bases de datos: una con datos a nivel nacional y otra con datos a nivel departamental.

La primera base de datos está constituida por series nacionales anuales que cubren el período que va desde 1848 hasta 2010. Específicamente, la información anual de nacimientos, que distingue entre legítimos (hijo de madre casada) e ilegítimos (hijo de madre no casada), así como los datos de matrimonios, provienen de diferentes fuentes. Para el período 1848-1906, se usan las estadísticas retrospectivas publicadas en el Anuario Estadístico de la República de Chile, vol. I, Demografía, año 1925 (Oficina Central de Estadística 1926, 78 y 79). Para el período 1907-1951, la base es la estadística retrospectiva del Servicio Nacional de Estadística y Censos (1951, 2 y 3), Demografía y asistencia social, año 1951. Finalmente, las cifras del período 1952-2010 provienen de la revisión año a año de diferentes volúmenes con información demográfica ("Demografía", "Anuario de estadísticas vitales" o "Estadísticas vitales"), publicados por el Instituto Nacional de Estadísticas (INE) y sus predecesores. Otros datos demográficos, como la serie de población total, provienen de Díaz et al. (2016). ${ }^{4}$

La segunda base de datos, que constituye una de las innovaciones de este trabajo, proviene de la recopilación de información a nivel departamental que cubre antecedentes desde 1862 hasta 1948. Esta base es relevante porque nos permite, primero, evaluar si los datos nacionales ocultan heterogeneidad en el país, tanto en niveles como en tendencia. Y

${ }^{4}$ La calidad de las series demográficas es bastante buena, considerando las regulares revisiones retrospectivas. Ver Mamalakis (1978). 
segundo, la base nos permite evaluar mejor algunas hipótesis planteadas, dado que podemos excluir factores específicos a algunas regiones que no cambian a través del tiempo, y también factores comunes a todas las comunas que evolucionan de manera conjunta. De esta manera, si algunos elementos que podrían confundir el análisis son influenciados por tendencias nacionales o por factores locales fijos en el tiempo podemos tener más certeza de que nuestro análisis no los incluyen.

A continuación describimos en detalle la construcción de estos datos. La fracción de niños nacidos fuera del matrimonio proviene de los anuarios estadísticos de Chile para 1862, 1870, 1876, 1879, 1887, 1896, 1910, 1914, 1918, 1921, 1924, 1927, 1930, 1931, 1933-40, 1943 у 1948. En concreto, se digitalizó la cantidad de nacimientos, el número de niños legítimos e ilegítimos por departamentos y circunscripciones. En los primeros años la información está disponible sólo por parroquias. A partir de 1910, tenemos además datos sobre el número de matrimonios para cada año. Para los años desde 1933, existe adicionalmente la fracción de matrimonios que legitiman hijos al casarse por provincias.

Se incluyen todos los departamentos de Chile a partir de su incorporación en los anuarios. Por ejemplo, la región de Arica sólo ingresa tras la Guerra del Pacífico y Magallanes lo hace una vez que es colonizado. Los departamentos se crean en Chile a partir de la Constitución de 1823 y equivalían a las antiguas intendencias. Corresponden a una unidad administrativa del país ubicada entre la provincia (unidad mayor) y las subdelegaciones y distritos (unidades menores), y son entidades más grandes que las comunas de hoy. Dado que hay muchos cambios en los límites geográficos de cada departamento, se forman unidades geográficas constantes a través del tiempo juntando circunscripciones o departamentos. Eso nos genera un máximo de 62 unidades geográficas que denotamos como "departamentos" a través del tiempo. Para los años anteriores a 1896 tenemos menos unidades geográficas, empezando con sólo 45 y subiendo paulatinamente con el paso del tiempo.

A los datos de ilegitimidad agregamos información sobre las condiciones locales de cada unidad geográfica, replicando la unificación de departamentos o circunscripciones para generar zonas idénticas a las anteriores. Los datos de la razón de género, de la fracción de la población urbana y de la población total por departamento vienen de los censos de población desde 1865 hasta 1940. Además, existe información disponible para los años 1865, 1875, 1895, 1907, 1920 y 1940 para 
las ocupaciones de los individuos por departamento. Estas ocupaciones se clasificación en agricultura, minería, industria y otros, siguiendo la clasificación hecha por Forero et al. (2015) para el período 1865-1920. Para 1940 se usa la clasificación industrial propuesta por el censo de ese año.

Finalmente, se incluyen otras variables a nivel de departamento que pueden estar relacionadas con las variables de interés, particularmente, datos sobre la existencia de puertos. Ello, dado que hay trabajos que documentan que la operación de puertos tiene implicancias en las tasas de matrimonios, fertilidad e ilegitimidad (Lawton y Lee 2002). En este caso, los puertos se clasifican en "grandes" si permiten el acceso de barcos internacionales, y "pequeños" si no lo permiten, con todo lo que ello implica. Para esta clasificación se usan los datos de Cuesta et al. (2015) para puertos grandes y los datos de los anuarios estadísticos para los puertos chicos (en este caso solamente tenemos observaciones hasta 1910). ${ }^{5}$

\section{DATOS AGREGADOS Y COMPARACIÓN INTERNACIONAL}

El gráfico 1 presenta la evolución de la tasa de natalidad entre 1848 y 2010 distinguiendo entre los inscritos como legítimos e ilegítimos. Es posible observar que la proporción de niños nacidos fuera del matrimonio registra un incremento desde el comienzo de la muestra hasta aproximadamente 1920, para luego tener una caída que culmina en la década de los 1960 y después aumentar fuertemente en el período final de la muestra.

El gráfico 2, a su vez, presenta la evolución temporal de la fracción de niños nacidos fuera del matrimonio y el número de matrimonios por cada 1.000 personas desde 1848 hasta 2010. La evolución de la tasa de matrimonios tiende a relacionarse inversamente con esta variable: la caída de la tasa de matrimonios en torno a 1880 justamente coincide con el aumento del porcentaje de niños que nacen fuera del matrimonio. Luego el aumento en la tasa de matrimonios que se produce desde fines de la década de 1910 es precisamente contemporáneo con el comienzo en la caída de la tasa de ilegitimidad. Para luego, a finales del siglo XX, caer fuertemente justo cuando el porcentaje de niños nacidos fuera del matrimonio aumenta.

${ }^{5}$ La serie de datos anual está disponible en Díaz et al. (2016) y la de los datos departamentales se puede solicitar a los autores de este trabajo. 
Gráfico 1. TASA DE NATALIDAD POR CADA 1.000 PERSONAS Y PROPORCIÓN DE NIÑOS NACIDOS FUERA DEL MATRIMONIO

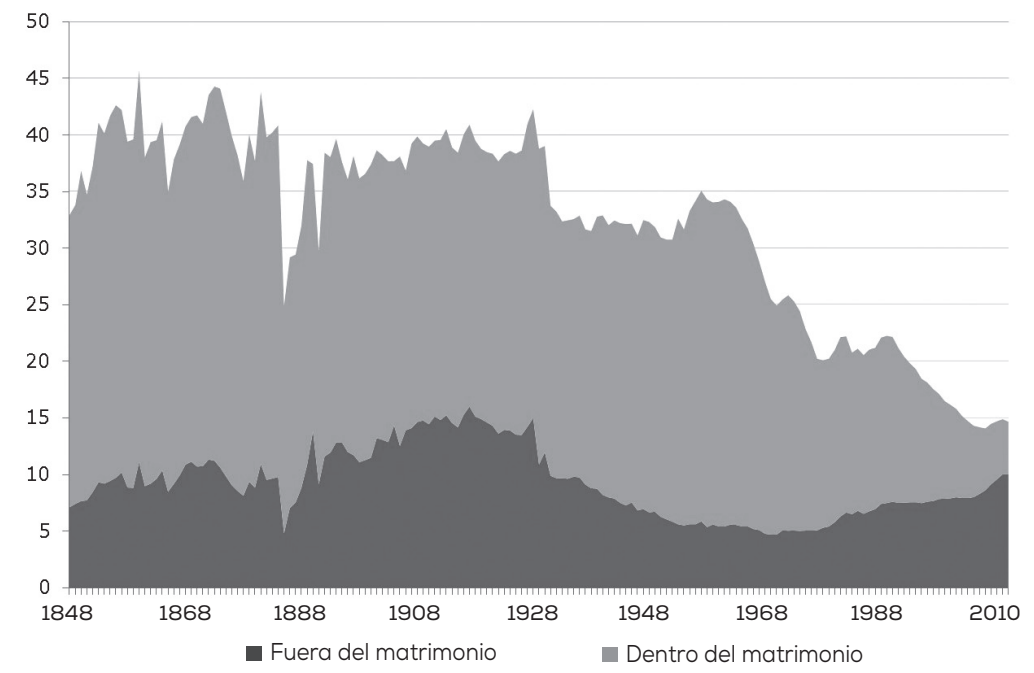

Fuente: Diaz et al. (2016) basado en antecedentes de la Oficina Central de Estadística, el Servicio Nacional de Estadística y Censos, y el Instituto Nacional de Estadísticas.

Las hipótesis planteadas inicialmente son difíciles de evaluar a un nivel agregado. Por ejemplo, si tomamos la hipótesis de que los costos del matrimonio eran prohibitivos, podríamos pensar que periodos de crecimiento económico deberían corresponder a periodos de menor tasa de ilegitimidad, dado que a mayor riqueza la barrera de acumulación de activos se podría superar de manera más sencilla. Pero el gráfico 1 no parece indicar que en periodos de auge económico Chile habría tenido necesariamente menos nacimientos fuera del matrimonio. Además, el gráfico no demuestra una fuerte correlación entre ciclos económicos y tasa de ilegitimidad. Ahora bien, hay varios otros cambios que ocurren en el periodo, al mismo tiempo que los económicos, que pueden explicar estas tendencias. Para poder lograr aislar los efectos de ingreso, ${ }^{6}$ de cambios demográficos, etcétera, nos concentraremos en el análisis

${ }^{6}$ Efecto ingreso — o de ingreso- se refiere a modificaciones en las decisiones del agente como resultado de un cambio en el ingreso. Por ejemplo, en este contexto, un aumento de ingreso (aproximado por un aumento de la población) reduce la tasa de ilegitimidad. 
Gráfico 2. TASAS DE MATRIMONIOS POR CADA 1.000 PERSONAS Y PROPORCIÓN DE NIÑOS NACIDOS FUERA DEL MATRIMONIO

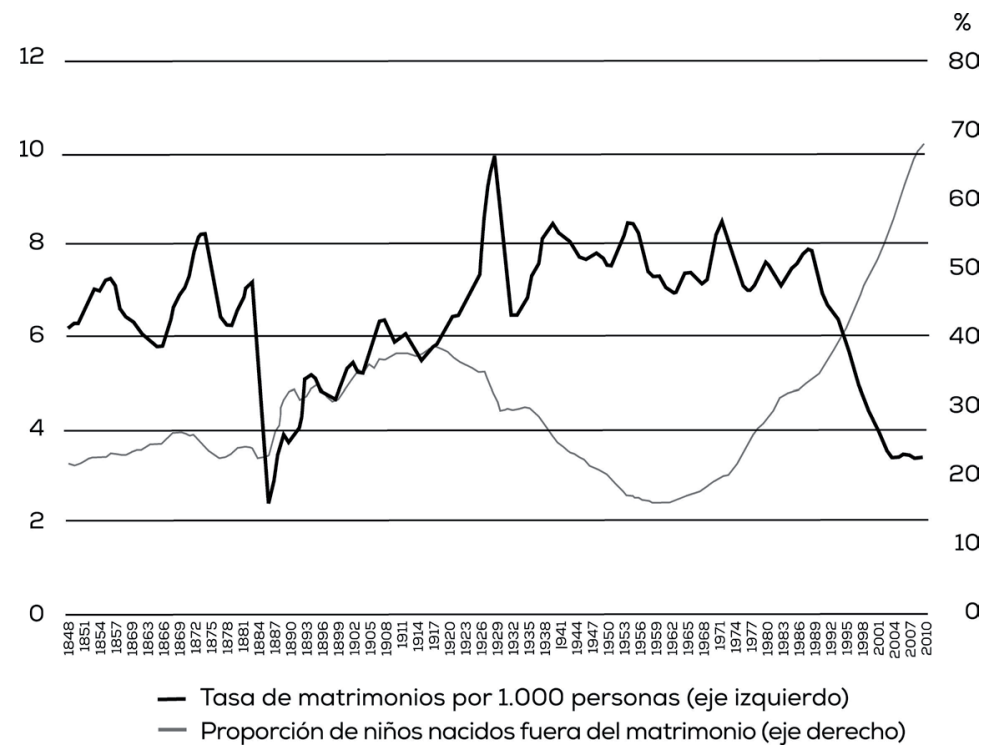

Fuente: Diaz et al. (2016) basado en antecedentes de la Oficina Central de Estadística, el Servicio Nacional de Estadistica y Censos, y el Instituto Nacional de Estadisticas.

departamental, donde podemos controlar por elementos temporales comunes a todas las regiones de Chile.

Aunque el objetivo de este trabajo no es realizar una comparación internacional, los gráficos 3 y 4 ponen esta evolución en perspectiva internacional, al comparar las cifras de Chile con cifras para Estados Unidos y el Reino Unido (países para los cuales se tiene disponible una serie larga de datos de ambas variables). ${ }^{7}$

${ }^{7}$ Los datos de EE.UU. provienen de las siguientes fuentes. Población total: Johnston y Williamson (2016). Nacidos vivos: 2000-2010: Martin et al. (2015); 1985-1999: Martin et al. (2002) Table 1; 1909-1984: USBC (2012). Nacimientos fuera del matrimonio (nivel y tasa): 2000-2010: Martin et al. (2015); 1985-1999: Martin et al. (2002); 1940-1984: Ventura y Bachrach (2000). Las cifras de Inglaterra y Gales provienen de las siguientes fuentes. Población total: interpolación spline considerando las siguientes fuentes y años, Mitchell (1988), años 1801, 1811, 1821, 1831, 1841, 1851, 1861, 1871, 1881, 1891, 1901, 1911, 1921, 1931, 1939, 1951, 1961, 1971, 1981; Office for National Statistics (http://www.ons.gov.uk), años 1991, 2001, 2014. Nacidos vivos y nacimientos fuera del matrimonio (nivel y tasa): 1999-2012: Office for National Statistics (http://www.ons.gov.uk); 1848-1998: series facilitadas por John Ermisch (2008). 
Gráfico 3. PORCENTAJE DE NIÑOS NACIDOS FUERA DEL MATRIMONIO

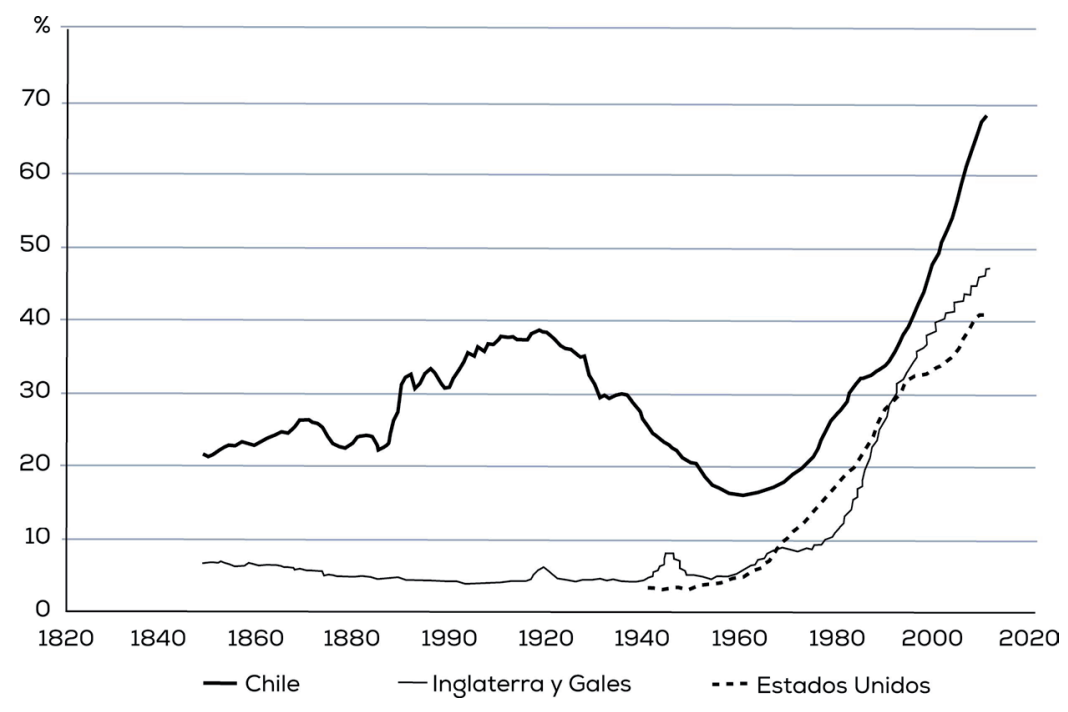

Fuente: Ver nota 7.

Respecto de la tasa de niños nacidos fuera del matrimonio, llaman la atención tres patrones respecto de esta comparación: (i) la mayor tasa de ilegitimidad en Chile, a lo largo de la historia, especialmente respecto de lo que sucede en el siglo XIX; (ii) el repunte de la tasa de ilegitimidad desde mediados del siglo XX, lo que también sucede en los tres países y que probablemente captura tendencias culturales internacionales; y (iii) el aumento que se produce a fines del siglo XIX y comienzos del siglo XX parece ser un fenómeno local, lo que motiva con mayor fuerza el ejercicio a nivel departamental que realizamos más abajo, para, precisamente, ese período. ¿Es posible que la tasa superior de Chile respecto a estos dos países esté correlacionada con la pobreza relativa de Chile comparada con los mismos países (lo que haría que el costo de formar una pareja fuese más alto en Chile que en EE.UU. o el Reino Unido)?

Respecto de la tasa de matrimonios, la comparación de los datos para Chile con los otros países que se presenta en el gráfico 4 sugiere nuevamente similitudes y diferencias. Por un lado, durante el siglo XIX la tasa de matrimonios respecto de la población en Chile fue significativamente más baja que en los otros dos países considerados. Por otro lado, la caída que se observa a fines del siglo XX también se observa 
Gráfico 4. MATRIMONIOS POR CADA 1.000 PERSONAS

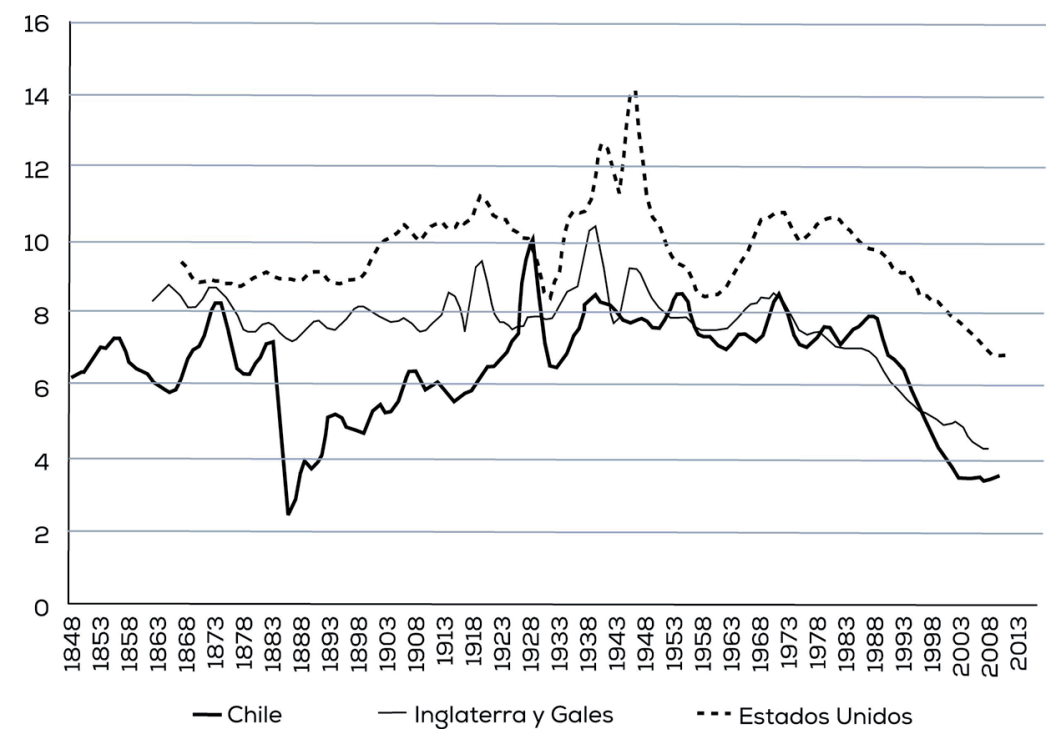

Fuente: Ver nota 7.

en los otros países. La diferencia más importante parece relacionarse nuevamente con el comportamiento que se observa en Chile a fines del siglo XIX y comienzos del XX, cuando incluso el país converge a una tasa de matrimonios similar a la del Reino Unido. Llaman también la atención las mayores fluctuaciones de esta tasa respecto de la tasa de ilegitimidad. Por ejemplo, en Estados Unidos es bastante notorio el efecto de la Gran Depresión y de la Segunda Guerra Mundial en la tasa de matrimonios, situación que no se observa para la tasa de ilegitimidad.

Comparaciones con otros países diferentes a Estados Unidos e Inglaterra y Gales respecto de la tasa de ilegitimidad, especialmente menos desarrollados, no son fáciles de realizar debido a que no existen series largas de datos, especialmente para el siglo XIX. Hartley (1975) presenta alguna información para el período que discutimos, y lo expuesto previamente para Estados Unidos y el Reino Unido parece ser representativo de muchos otros países desarrollados. Un grupo de naciones con mayores tasas de ilegitimidad durante fines del siglo XIX corresponde a los países escandinavos y algunos de Europa Continental. 
De hecho, los únicos que presentan tasas de ilegitimidad que se acercan al nivel observado para Chile en este período son Islandia y Austria. En el primer caso, Islandia presenta valores en promedio cercanos al 25 por ciento pero con una caída hacia valores en torno al 13 por ciento en las dos primeras décadas del siglo XX. Para el caso de Austria se observa un máximo de 25,6 por ciento para el período 1926-1930, que parten de un mínimo de 12,2 por ciento en 1906-1910 y luego caen a un mínimo de 13,2 por ciento en 1940, para después volver a subir durante la Segunda Guerra Mundial.

Respecto de la baja en la tasa de ilegitimidad que se observa para el período posterior a 1930, es interesante notar que no es una tendencia que sea claramente observable ni a nivel mundial ni en otros países de América Latina. El gráfico 5 presenta información para un grupo de países de América Latina para años en torno a 1930, 1950 y 1965. Como es posible ver, la gran caída que se observa para Chile (básicamente una baja desde 32 a 17 por ciento) sólo es parcialmente comparable con lo que se observa para Uruguay (que baja de 29 a 20 por ciento). Los otros países no presentan una tendencia tan clara a la baja como la observada en el caso de Chile. De hecho, Chile pasa de ser el cuarto país con tasa más alta de ilegitimidad a ser el país con la tasa más baja. Todo esto parece sugerir que el período de fines del siglo XIX $\mathrm{y}$ comienzos del siglo XX, en que notamos un aumento y luego una reversión que culmina en torno a mediados de los 1950, es un período de especial interés, lo que motiva nuestro ejercicio a nivel departamental en la siguiente sección.

Como hemos mencionado antes, no existe evidencia sistemática disponible para el período previo a 1930 para la mayor parte de los países de América Latina. Sin embargo, existen diferentes discusiones y conjeturas respecto de la situación en el siglo XIX (e incluso en períodos previos). Por ejemplo, para el período colonial Newson (2006) postula una tasa de ilegitimidad del orden del 40 por ciento relacionada fuertemente con la existencia de población mestiza, un punto también mencionado por Borah y Cook (1966). En el caso de la ciudad de México, García (2004) sugiere que la ilegitimidad se mantuvo alrededor del 20 por ciento para la mayor parte del siglo XIX.

En el caso de Argentina, Mateo (1996) concluye que la tasa de ilegitimidad es similar a lo observado en otras regiones de América y 
Gráfico 5. PORCENTAJE DE NACIDOS FUERA DEL MATRIMONIO EN AMÉRICA LATINA

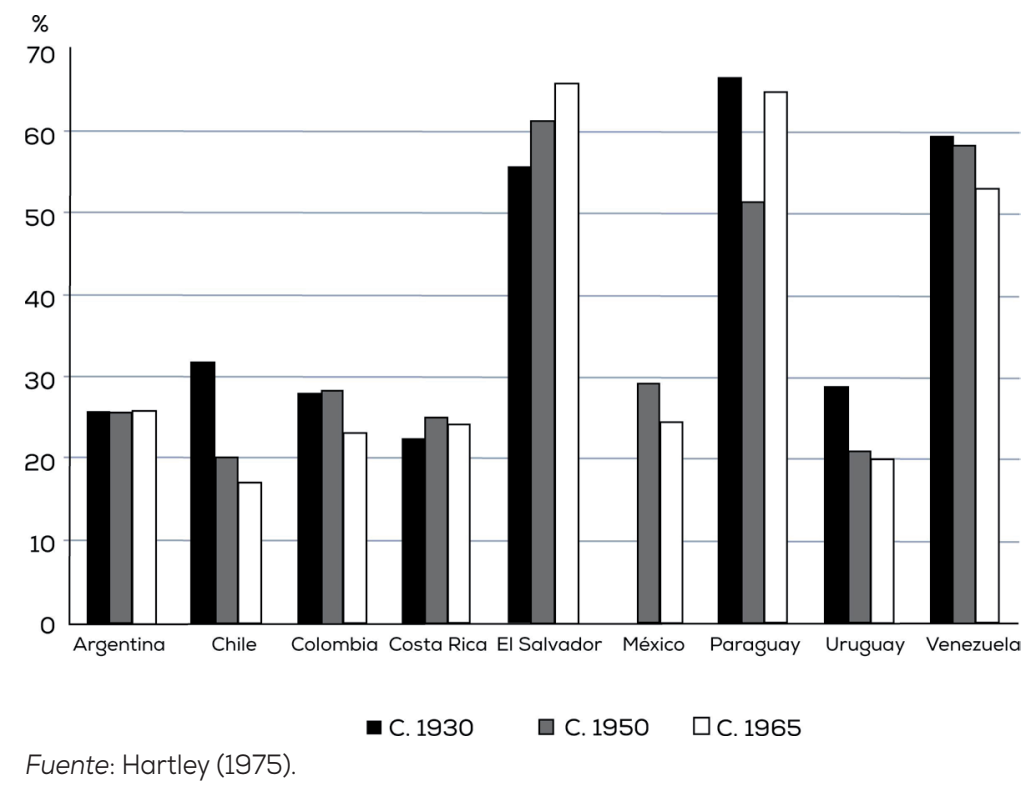

su evolución es creciente durante la primera mitad del siglo XIX para descender en vísperas del siglo XX. Otero (2006) calcula que la ilegitimidad en Argentina es de alrededor de 21 por ciento hacia 1914, pero con mucha heterogeneidad entre provincias (67 por ciento en Formosa; 8 por ciento en Santa Cruz)

Un último elemento relevante a considerar cuando se observan las tasas de ilegitimidad planteadas para Chile corresponde a la "legitimización" que parece existir en diferentes momentos de la historia. Como argumentamos previamente, no tenemos datos para todo el período sino que sólo para algunos años de las décadas de 1930 y 1940. En particular, para 1933 y 1934 tenemos el número total de niños legitimizados. Si se netea la ilegitimidad de esos años la tasa baja desde un promedio de 29 por ciento a un promedio de 18,5. Esto es consistente con el argumento de McCaa (1983) para el valle de Petorca entre 1840 y 1976. Más aún, es interesante notar que en esos mismos años algo más del 24 por ciento de los matrimonios legitimizaron hijos y, en promedio, cada matrimonio legitimizó 2,4 niños. Eso habla de uniones de hecho con más de un hijo en promedio que luego se convierten en matrimonios. Tenemos tam- 
bién datos disponibles para 1933-1948. En ese período el porcentaje de matrimonios que legitimiza tiene un promedio de 25 por ciento con un máximo de 28,8 en 1939 y un mínimo de 20,1 en 1948. Esto sugiere que la legitimización no es un fenómeno aislado a algunos años.

\section{ILEGITIMIDAD Y MATRIMONIO A NIVEL DEPARTAMENTAL EN CHILE}

La sección anterior presenta la evolución chilena con datos para la república. Pero, como discutimos antes, esta evolución agregada puede ocultar diferencias a nivel regional que podrían dar más indicaciones de las cualidades del fenómeno, lo que motiva la exploración a nivel de departamentos.

Empezamos mostrando las estadísticas de la muestra y su descomposición a través del tiempo en la tabla 1 . La tabla 2 separa los departamentos por zonas geográficas.

La tabla 1 muestra que en promedio la tasa de ilegitimidad era de 30 por ciento en los departamentos de Chile, número bastante constante antes y después de 1920. Pero también se aprecia mucha varianza entre

Tabla 1. RESUMEN DE LAS ESTADÍSTICAS DE LA BASE DEPARTAMENTAL, ANTES Y DESPUÉS DE 1920

\begin{tabular}{lcccccc}
\hline & \multicolumn{2}{c}{ Total } & \multicolumn{2}{c}{ Antes 1920} & \multicolumn{2}{c}{ Después 1920 } \\
\hline & Media & Desv. est. & Media & Desv. est. & Media & Desv. est. \\
\hline $\begin{array}{l}\text { \% niños nacidos fuera del } \\
\text { matrimonio }\end{array}$ & 0,310 & 0,107 & 0,309 & 0,116 & 0,311 & 0,100 \\
$\begin{array}{l}\text { Razón de hombres a } \\
\text { mujeres }\end{array}$ & 1,037 & 0,166 & 1,044 & 0,182 & 1,031 & 0,150 \\
\% población urbana & 0,328 & 0,235 & 0,288 & 0,25 & 0,362 & 0,216 \\
Log (población) & 10,577 & 0,869 & 10,399 & 0,858 & 10,732 & 0,849 \\
Log (nacimientos) & 7,301 & 0,879 & 7,106 & 0,870 & 7,474 & 0,851 \\
Puerto grande & 0,052 & 0,222 & 0,043 & 0,204 & 0,059 & 0,236 \\
Puerto chico & 0,263 & 0,441 & 0,227 & 0,419 & 0,297 & 0,457 \\
\% empleo agricola & 0,394 & 0,226 & 0,406 & 0,193 & 0,379 & 0,260 \\
\% empleo minería & 0,039 & 0,084 & 0,036 & 0,072 & 0,043 & 0,097 \\
\% empleo manufactura & 0,162 & 0,113 & 0,221 & 0,119 & 0,091 & 0,042 \\
\hline
\end{tabular}


Tabla 2. RESUMEN DE LAS ESTADÍSTICAS DE LA BASE DEPARTAMENTAL, POR ZONA GEOGRÁFICA

\begin{tabular}{lcccccc}
\hline & \multicolumn{2}{c}{ Norte } & \multicolumn{2}{c}{ Centro } & \multicolumn{2}{c}{ Sur } \\
\hline & Media & Desv. est. & Media & Desv. est. & Media & Desv. est. \\
\hline $\begin{array}{l}\text { \% niños nacidos fuera del } \\
\text { matrimonio }\end{array}$ & 0,415 & 0,102 & 0,255 & 0,078 & 0,297 & 0,090 \\
$\begin{array}{l}\text { Razón de hombres a } \\
\text { mujeres }\end{array}$ & 1,133 & 0,241 & 0,989 & 0,068 & 1,022 & 0,147 \\
$\begin{array}{l}\text { \% población urbana } \\
\text { Log (población) }\end{array}$ & 0,431 & 0,246 & 0,328 & 0,228 & 0,27 & 0,215 \\
Log (nacimientos) & 10,155 & 0,700 & 10,887 & 0,813 & 10,566 & 0,898 \\
Puerto grande & 7,301 & 0,879 & 7,106 & 0,870 & 7,474 & 0,851 \\
Puerto chico & 6,869 & 0,771 & 7,579 & 0,845 & 7,314 & 0,869 \\
\% empleo agricola & 0,023 & 0,150 & 0,051 & 0,22 & 0,069 & 0,254 \\
\% empleo mineria & 0,298 & 0,233 & 0,428 & 0,199 & 0,418 & 0,230 \\
\% empleo manufactura & 0,085 & 0,114 & 0,017 & 0,038 & 0,032 & 0,084 \\
\hline
\end{tabular}

los departamentos, con una desviación estándar equivalente a un tercio de la media. A su vez, la tabla 2 identifica que hay variación importante entre regiones, con el norte teniendo la tasa más importante de ilegitimidad, seguido del sur. Pero, aun así, hay bastante diferencia (varianza) al interior de cada región, entre departamentos y a través del tiempo, como lo indica la desviación estándar.

Por ejemplo, en 1862 el promedio de tasa de ilegitimidad es de 24,6 por ciento, pero hay departamentos que tienen tasas bajo 10 por ciento, como Castro, y otros con tasas sobre 40, como Coronel, Copiapó y Elqui. En 1918, año en que el promedio de la tasa de ilegitimidad sube a 38,8 por ciento, también se observa una amplia varianza. Mientras existen departamentos con tasas iguales o menores al 20 por ciento (como Quinchao, San Fernando y Magallanes), hay otros departamentos con tasas iguales o superiores al 55 por ciento (como Copiapó, Llanquihue, Elqui, Coquimbo, Ovalle y Huasco). Finalmente, lo mismo ocurre en 1948, en que la tasa de ilegitimidad decrece a 26,1 por ciento en promedio, pero nuevamente observamos una alta heterogeneidad: departamentos con tasas de ilegitimidad iguales o menores al 15 por ciento (como Caupolicán, San Fernando, Rancagua y Curicó) y otros 
departamentos que continúan con tasas sobre el 40 (como Elqui, Huasco, Ovalle y Combarbalá). Si bien se pueden plantear explicaciones idiosincrásicas para cada uno de los casos, la idea es recurrir a nuestro análisis empírico para establecer correlatos empíricos robustos.

La tabla 1 también muestra varianza en las variables explicativas que vamos a evaluar en el modelo empírico. La razón de género favorecía levemente a los hombres tanto antes como después de 1920, pero mucho más en algunas regiones - Norte - que en otras. Chile vivió un episodio de urbanización reflejado en el aumento de la fracción urbana promedio en el período de nuestra muestra (1862-1948). Los departamentos promedios viven una caída de la agricultura y de la actividad manufacturera (a veces artesanal) y un alza del sector servicios. Hay un crecimiento de la población y de los nacimientos, que son más altos en la Zona Central. Finalmente, los puertos están más concentrados en la Zona Central y Sur que en el Norte, y no hay mucha diferencia antes y después de 1920.

Respecto de la tasa de matrimonios por cada 1.000 personas, para la cual tenemos disponibles datos a nivel departamental desde 1910, también se observa una alta heterogeneidad entre departamentos. Por ejemplo, mientras en 1918 la tasa de matrimonios por cada 1.000 personas era 5,8 en promedio, algunos departamentos tenían tasas inferiores a 3,5 —como Combarbalá, Cachapoal, Ovalle, Llanquihue, Castro e Imperial- y otros departamentos presentaban tasas mayores a 8 - como Coronel, Tocopilla, Constitución, Rancagua, Loncomilla y Chañaral- Esta heterogeneidad también se observa en 1948, cuando la tasa de matrimonios sube a 7,8. Sin embargo, aún existen departamentos con tasas menores a 5 -como Combarbalá, Huasco y Ovalle-, junto con otros departamentos con tasas superiores a $10-$ como Quillota, Tocopilla, Valparaíso, Lontué, Antofagasta y Santiago-. Nuevamente dejamos al análisis empírico intentar las razones que puedan explicar esta diversidad.

Habiendo descrito brevemente los datos, ahora vamos a definir la estrategia empírica que vamos a utilizar. En esta sección realizamos una investigación empírica respecto de las variables correlacionadas con la tasa de ilegitimidad y de matrimonios en un panel de departamentos chilenos entre 1862 y 1948. Como hemos argumentado más atrás, este período corresponde a un momento especial en la evolución de la tasa de ilegitimidad, que ha recibido bastante atención en la literatura. 
La idea básica es buscar correlatos de la tasa de ilegitimidad (para el período que va desde 1862 hasta 1948) y de la tasa de matrimonios (para el período que va desde 1910 a 1948) y para ello estimaremos regresiones de panel de la siguiente forma:

$$
y_{i t}=x_{i t}^{\prime} \beta+\eta_{i}+\eta_{t}+\varepsilon_{i t},
$$

donde $i$ se refiere a departamento y $t$ a año. La variable $y$ corresponde a la variable que queremos explicar (en nuestro caso, la tasa de ilegitimidad y la tasa de matrimonios), $x$ es un vector de potenciales correlatos de la variable que queremos explicar, $\eta_{i}$ son efectos por departamento (para capturar diferentes niveles de la variable y que no cambian en el tiempo), $\eta_{t}$ son efectos por tiempo (para capturar diferentes niveles de la variable que son comunes para todos los departamentos en un año específico) y $\varepsilon_{i t}$ es un efecto no observable para nosotros que varía por departamento y por año. ${ }^{8}$ Nuestro análisis empírico nos permite medir cómo cambios en las variables explicativas están correlacionados con cambios en la tasa de ilegitimidad, esperando que el uso de efectos fijos limpie potenciales factores que podrían determinar de manera simultánea la variable explicativa y la tasa de ilegitimidad.

En el caso de la tasa de ilegitimidad, presentaremos estimaciones para el período 1862-1948 y, además, para los subperíodos 1862-1918 y 1921-1948. La idea de esta división es estudiar si las estimaciones cambian cuando nos enfocamos en el período de auge de la minería del salitre (hasta la década de 1910) y después de ello. En el caso de la tasa de matrimonios, disponemos de información por departamento sólo a partir desde 1910, por lo que no podemos realizar análisis por subperíodos.

Las variables que vamos a evaluar están determinadas por nuestra revisión de las hipótesis planteadas para explicar la natalidad fuera del matrimonio. Para poder medir si el impacto del poder de negociación entre hombres y mujeres puede ser relevante, incluimos la razón del número de hombres por mujeres en la población. La teoría económica nos sugiere que entre más alto sea este valor, más poder de negociación ten-

${ }^{8}$ En términos más técnicos, luego de utilizar un test de Hausman vamos a suponer que $\eta_{i}$ no está correlacionado con el vector de variables $x$ y que se distribuye con normalidad. Es decir, vamos a suponer un modelo de efectos aleatorios a nivel de departamento. 
drán las mujeres y, en consecuencia, será menos probable que los niños nazcan fuera del matrimonio.

Medimos después la hipótesis de que la gente enfrenta una restricción para llevar a cabo el matrimonio a causa de la pobreza, lo que podría explicar la legalización de los hijos al momento del matrimonio. Mientras que el costo legal del matrimonio debería ser igual para todas las regiones, un ingreso más alto debería permitir pagar este costo más fácilmente. Como no tenemos medidas de ingreso a nivel departamental, usamos el logaritmo de la población, que es una proxy relacionada con el ingreso local. Dado que el crecimiento de la población a veces viene acompañado por urbanización, incluimos también la fracción de la población que es urbana. Eso nos permite contrastar la tesis de Salazar (1990), que argumenta que el "huachismo" era una realidad rural, con la hipótesis de Rojas (2010) sobre el rol de las redes sociales más débiles en el sector urbano.

Finalmente, incluimos variables relacionadas con actividades económicas específicas para poder explorar en más detalles la hipótesis de Salazar y contrastarla con otras conjeturas, relacionadas con la calidad del empleo masculino (que podría ser mayor en minería y manufacturas que en el sector agrícola) y la llegada de hombres "de paso" de manera frecuente con la medición de puertos.

La tabla 3 presenta los resultados para las regresiones que correlacionan la tasa de ilegitimidad con características del departamento para el período completo. En las primeras dos columnas correlacionamos la tasa de ilegitimidad con tres variables departamentales que capturan elementos presentes en la discusión histórica y en la literatura económica sobre el tema: la razón de hombres a mujeres, el grado de urbanización y el tamaño de la población (como proxy también de desarrollo económico a nivel departamental).

Los resultados sugieren que no existe una correlación con la razón de hombres a mujeres. Por otro lado, aumentos en el nivel de urbanización a nivel departamental se asocian a aumentos de la tasa de ilegitimidad (como es sugerido por Rojas 2010), probablemente reflejando la existencia de relaciones menos personales en ciudades. A su vez, aumentos de la población del departamento se correlacionan negativamente con la ilegitimidad, sugiriendo probablemente un efecto ingreso relacionado con el desarrollo de los departamentos. Luego, en 
las columnas (3) y (4) agregamos dos variables relacionadas con las mismas que afectan la tasa de ilegitimidad: la tasa de matrimonios (sólo disponible desde 1910) y el número de nacimientos por departamento. Los resultados sugieren una correlación negativa y fuerte con la tasa de matrimonios (lo que es muy esperable, como hemos discutido más arriba). A su vez, los resultados sugieren que períodos de mayor natalidad se asocian con un aumento más que proporcional de los nacidos fuera del matrimonio. A su vez, los resultados sobre población total y tasa de urbanización se mantienen con los mismos signos y estadísticamente significativos.

En la columnas (5) a (7) analizamos la inclusión de variables relacionadas con los tipos de actividades económicas de los departamentos. En primer lugar, en la columna (5) agregamos variables que capturan la existencia de puertos. Los resultados sugieren que la existencia de puertos con acceso a rutas internacionales tiene un efecto positivo, significativo y grande en la tasa de ilegitimidad, confirmando resultados existentes en la literatura. En contraste, los puertos más pequeños (sin acceso a una alta población flotante internacional) tienen una correlación negativa con la tasa de ilegitimidad.

En la columna (6) agregamos la participación del empleo en agricultura, manufacturas y minería (dejando como categoría básica a la participación en el sector servicios). ${ }^{9}$ Los resultados sugieren que la participación agrícola parece correlacionarse negativamente con la tasa de ilegitimidad. Esto es consistente con los resultados previos sobre tasa de urbanización y nuevamente insinúan que el desarrollo de las ciudades (controlando por el tamaño de las mismas) se correlaciona positivamente con la ilegitimidad. Finalmente, la columna (7) combina las especificaciones de las columnas (5) y (6) y sugiere resultados muy similares a los de las columnas previas en términos de signos, aunque se pierde significancia estadística por la alta colinealidad existente entre las variables.

Las tablas 4 y 5 estudian si las correlaciones existentes se presentan antes y después de 1920. Mientras el período previo a 1920 corresponde básicamente al período de auge de la explotación minera del salitre, el período post 1920 corresponde a su declive y a la conso-

${ }^{9}$ El número de observaciones desciende porque no tenemos disponible esta información para todos los censos a nivel departamental. 
Tabla 3. TASA DE NACIDOS FUERA DEL MATRIMONIO, ESTIMACIONES A NIVEL DEPARTAMENTAL 1862-1948

\begin{tabular}{|c|c|c|c|c|c|c|c|}
\hline & \multicolumn{7}{|c|}{ Variable dependiente: Tasa de niños nacidos fuera del matrimonio } \\
\hline & (1) & (2) & (3) & (4) & $(5)$ & (6) & (7) \\
\hline $\begin{array}{l}\text { Razón de hombres } \\
\text { a mujeres }\end{array}$ & $\begin{array}{c}0,004 \\
(0,020)\end{array}$ & $\begin{array}{l}-0,001 \\
(0,020)\end{array}$ & $\begin{array}{c}0,012 \\
(0,020)\end{array}$ & $\begin{array}{c}0,001 \\
(0,020)\end{array}$ & $\begin{array}{c}0,006 \\
(0,020)\end{array}$ & $\begin{array}{c}0,019 \\
(0,023)\end{array}$ & $\begin{array}{c}0,027 \\
(0,023)\end{array}$ \\
\hline \% población urbana & $\begin{array}{l}0,041^{* * *} \\
(0,016)\end{array}$ & $\begin{array}{l}0,051^{* * *} \\
(0,016)\end{array}$ & $\begin{array}{l}0,085^{* * *} \\
(0,022)\end{array}$ & $\begin{array}{l}0,053^{* * *} \\
(0,016)\end{array}$ & $\begin{array}{l}0,046^{* * *} \\
(0,016)\end{array}$ & $\begin{array}{l}0,031^{*} \\
(0,018)\end{array}$ & $\begin{array}{c}0,028 \\
(0,018)\end{array}$ \\
\hline Log (población) & & $\begin{array}{l}-0,013^{* * *} \\
(0,004)\end{array}$ & $\begin{array}{l}-0,033^{* \star *} \\
(0,006)\end{array}$ & $\begin{array}{l}-0,026^{* * *} \\
(0,009)\end{array}$ & $\begin{array}{l}-0,015^{\star \star *} \\
(0,004)\end{array}$ & $\begin{array}{l}-0,011^{* *} \\
(0,005)\end{array}$ & $\begin{array}{l}-0,012^{* *} \\
(0,005)\end{array}$ \\
\hline $\begin{array}{l}\text { Matrimonios } \\
\text { por población }\end{array}$ & & & $\begin{array}{l}-4,284^{* * *} \\
(0,858)\end{array}$ & & & & \\
\hline $\begin{array}{l}\text { Log } \\
\text { (nacimientos) }\end{array}$ & & & & $\begin{array}{c}0,015^{*} \\
(0,009)\end{array}$ & & & \\
\hline Puerto grande & & & & & $\begin{array}{l}0,080^{* \star *} \\
(0,020)\end{array}$ & & $\begin{array}{l}0,057^{\star *} \\
(0,022)\end{array}$ \\
\hline Puerto chico & & & & & $\begin{array}{l}-0,031^{* * *} \\
(0,014)\end{array}$ & & $\begin{array}{l}-0,000 \\
(0,015)\end{array}$ \\
\hline $\begin{array}{l}\text { \% empleo } \\
\text { agrícola }\end{array}$ & & & & & & $\begin{array}{l}-0,057^{*} \\
(0,026)\end{array}$ & $\begin{array}{r}-0,037 \\
(0,026)\end{array}$ \\
\hline $\begin{array}{l}\text { \% empleo } \\
\text { minería }\end{array}$ & & & & & & $\begin{array}{l}-0,000 \\
(0,045)\end{array}$ & $\begin{array}{c}0,011 \\
(0,045)\end{array}$ \\
\hline $\begin{array}{l}\% \text { empleo } \\
\text { manufactura }\end{array}$ & & & & & & $\begin{array}{c}0,031 \\
(0,048)\end{array}$ & $\begin{array}{c}0,032 \\
(0,048)\end{array}$ \\
\hline $\begin{array}{l}\text { Número de } \\
\text { observaciones }\end{array}$ & 908 & 908 & 609 & 908 & 908 & 670 & 670 \\
\hline $\begin{array}{l}\text { Número de } \\
\text { departamentos }\end{array}$ & 62 & 62 & 62 & 62 & 62 & 62 & 62 \\
\hline R2 total & 0,24 & 0,27 & 0,3 & 0,27 & 0,22 & 0,31 & 0,31 \\
\hline R2 within & 0,49 & 0,49 & 0,66 & 0,49 & 0,51 & 0,55 & 0,56 \\
\hline R2 between & 0,07 & 0,12 & 0,1 & 0,13 & 0,02 & 0,12 & 0,1 \\
\hline
\end{tabular}

* coeficiente estadisticamente significativo al 10\%

${ }^{* *}$ coeficiente estadísticamente significativo al $5 \%$

${ }^{* * *}$ coeficiente estadisticamente significativo al $1 \%$ 
lidación de las reformas asociadas a la cuestión social. En general, no observamos diferencias robustas entre períodos (se debe hacer notar, sin embargo, que no agregamos la tasa de matrimonios en la tabla 4 porque no está disponible para nosotros antes de 1910 y que no agregamos las dummies de puertos porque en el período posterior a 1920 no hay suficiente varianza intradepartamentos). El único resultado diferente que se aprecia es que sólo se observa una correlación positiva entre nacimientos e ilegitimidad en el período pre 1920.

Los resultados del análisis departamental nos pueden ayudar también a entender las tendencias nacionales. Por ejemplo, el alza marcada de la tasa nacional de ilegitimidad hasta 1920 corresponde a un periodo de urbanización fuerte para Chile. Y puede ser que solamente después de esta fecha el efecto ingreso que documentamos llegara a frenar esa tendencia.

Finalmente, la tabla 6 presenta correlaciones de la tasa de matrimonios con las mismas variables consideradas en el análisis de los determinantes de la tasa de ilegitimidad. Como hemos argumentado previamente, existen argumentos tanto conceptuales como empíricos como para notar que los fenómenos que afectan a ambas variables están correlacionados. Los resultados sugieren que algunas de las fuerzas que se correlacionan con la tasa de ilegitimidad presentan un patrón similar en términos de efectos en la tasa de matrimonios, mientras que otras presentan un patrón diferente. Esto es interesante, porque sugiere que ilegitimidad y matrimonio si bien están relacionados son fenómenos distintos.

En concreto, el efecto de la población es positivo y significativo en la tasa de matrimonios, probablemente capturando un efecto ingreso positivo, como se documenta en la literatura. Por otro lado, los resultados de la tabla 6 sugieren una correlación positiva y robusta con la razón de hombres a mujeres, lo que es consistente con los resultados de la literatura internacional que implican un aumento del poder de negociación de las mujeres cuando esta variable aumenta, lo que lleva a un efecto positivo sobre la tasa de matrimonios. A su vez la urbanización parece tener una correlación positiva en la tasa de matrimonios, lo que puede ser una consecuencia de cambios en la estructura demográfica de la población, de efectos ingreso o por la existencia de una mayor oferta de servicios públicos que facilitan la realización de matrimonios. Finalmente, en términos de efectos de los tipos de actividad económica, parece existir una correlación negativa pero débil entre el porcentaje de población que 
Tabla 4. TASA DE NACIDOS FUERA DEL MATRIMONIO, ESTIMACIONES A NIVEL DEPARTAMENTAL 1862-1918

\begin{tabular}{|c|c|c|c|c|c|c|}
\hline \multicolumn{7}{|c|}{ Variable dependiente: Tasa de niños nacidos fuera del matrimonio } \\
\hline & (1) & (2) & (3) & (4) & $(5)$ & (6) \\
\hline \multirow{2}{*}{$\begin{array}{l}\text { Razón de hombres a } \\
\text { mujeres }\end{array}$} & $-0,027$ & $-0,031$ & $-0,025$ & $-0,023$ & $-0,035$ & $-0,032$ \\
\hline & $(0,032)$ & $(0,032)$ & $(0,032)$ & $(0,032)$ & $(0,033)$ & $(0,033)$ \\
\hline \multirow[t]{2}{*}{ \% población urbana } & $0,082^{\star \star *}$ & $0,088^{* \star *}$ & $0,088^{* \star *}$ & $0,078^{* * *}$ & $0,046^{*}$ & $0,043^{*}$ \\
\hline & $(0,023)$ & $(0,023)$ & $(0,023)$ & $(0,023)$ & $(0,025)$ & $(0,025)$ \\
\hline \multirow[t]{2}{*}{ Log (población) } & & $-0,018^{\star \star \star}$ & $-0,034^{* * *}$ & $-0,021^{* \star *}$ & $-0,013^{*}$ & $-0,015^{* *}$ \\
\hline & & $(0,007)$ & $(0,013)$ & $(0,007)$ & $(0,007)$ & $(0,007)$ \\
\hline \multirow[t]{2}{*}{ Log (nacimientos) } & & & 0,019 & & & \\
\hline & & & $(0,013)$ & & & \\
\hline \multirow[t]{2}{*}{ Puerto grande } & & & & $0,136^{* * \star}$ & & $0,086^{* *}$ \\
\hline & & & & $(0,034)$ & & $(0,034)$ \\
\hline \multirow[t]{2}{*}{ Puerto chico } & & & & $0,008^{* * *}$ & & 0,027 \\
\hline & & & & $(0,017)$ & & $(0,017)$ \\
\hline \multirow[t]{2}{*}{ \% empleo agricola } & & & & & $-0,147^{* \star *}$ & $-0,102^{*}$ \\
\hline & & & & & $(0,054)$ & $(0,055)$ \\
\hline \multirow[t]{2}{*}{ \% empleo minería } & & & & & 0,067 & 0,083 \\
\hline & & & & & $(0,091)$ & $(0,091)$ \\
\hline \multirow{2}{*}{$\begin{array}{l}\% \text { empleo } \\
\text { manufactura }\end{array}$} & & & & & $-0,005$ & 0,026 \\
\hline & & & & & $(0,068)$ & $(0,068)$ \\
\hline $\begin{array}{l}\text { Número de } \\
\text { observaciones }\end{array}$ & 421 & 421 & 421 & 421 & 365 & 365 \\
\hline $\begin{array}{l}\text { Número de } \\
\text { departamentos }\end{array}$ & 61 & 61 & 61 & 61 & 61 & 61 \\
\hline R2 total & 0,28 & 0,31 & 0,31 & 0,27 & 0,43 & 0,41 \\
\hline R2 within & 0,46 & 0,46 & 0,47 & 0,5 & 0,49 & 0,52 \\
\hline R2 between & 0,23 & 0,27 & 0,26 & 0,17 & 0,45 & 0,39 \\
\hline
\end{tabular}

* coeficiente estadisticamente significativo al $10 \%$

** coeficiente estadisticamente significativo al $5 \%$

${ }^{* * *}$ coeficiente estadisticamente significativo al $1 \%$

trabaja en manufacturas y la tasa de matrimonios, lo que puede reflejar la existencia de costos de oportunidad en términos de oportunidades en el mercado laboral.

En suma, los resultados de las tablas 3 a 5 sugieren que tanto la tasa de ilegitimidad como la tasa de matrimonios están relacionadas con variables que presentan fuertes movimientos en el período bajo estudio. Esto es importante porque, como hemos dicho antes, el período en que nos enfocamos presenta variaciones importantes en dimensiones 
Tabla 5. TASA DE NACIDOS FUERA DEL MATRIMONIO, ESTIMACIONES A NIVEL DEPARTAMENTAL 1921-1948

\begin{tabular}{|c|c|c|c|c|c|}
\hline \multicolumn{6}{|c|}{ Variable dependiente: Tasa de niños nacidos fuera del matrimonio } \\
\hline & (1) & (2) & (3) & (4) & (5) \\
\hline \multirow[t]{2}{*}{$\begin{array}{l}\text { Razón de hombres a } \\
\text { mujeres }\end{array}$} & 0,006 & 0,012 & 0,015 & 0,011 & 0,05 \\
\hline & $(0,025)$ & $(0,025)$ & $(0,024)$ & $(0,025)$ & $(0,032)$ \\
\hline \multirow[t]{2}{*}{ \% población urbana } & $0,059^{* *}$ & $0,072^{* * *}$ & $0,072^{* * *}$ & $0,072^{* * *}$ & $0,061^{* *}$ \\
\hline & $(0,024)$ & $(0,025)$ & $(0,024)$ & $(0,025)$ & $(0,029)$ \\
\hline \multirow[t]{2}{*}{ Log (población) } & & $-0,020^{* * *}$ & $-0,020^{* * *}$ & $-0,018$ & $-0,028^{* * *}$ \\
\hline & & $(0,008)$ & $(0,007)$ & $(0,012)$ & $(0,009)$ \\
\hline \multirow[t]{2}{*}{ Matrimonios por población } & & & $-3,539^{* * *}$ & & \\
\hline & & & $(0,870)$ & & \\
\hline \multirow[t]{2}{*}{ Log (nacimientos) } & & & & $-0,002$ & \\
\hline & & & & $(0,011)$ & \\
\hline \multirow[t]{2}{*}{ \% empleo agrícola } & & & & & $-0,057^{\star}$ \\
\hline & & & & & $(0,035)$ \\
\hline \multirow[t]{2}{*}{ \% empleo minería } & & & & & 0,04 \\
\hline & & & & & $(0,057)$ \\
\hline \multirow[t]{2}{*}{ \% empleo manufactura } & & & & & $-0,181$ \\
\hline & & & & & $(0,124)$ \\
\hline Número de observaciones & 487 & 487 & 487 & 487 & 487 \\
\hline Número de departamentos & 62 & 62 & 62 & 62 & 62 \\
\hline R2 total & 0,23 & 0,25 & 0,29 & 0,25 & 0,23 \\
\hline R2 within & 0,66 & 0,66 & 0,67 & 0,66 & 0,66 \\
\hline R2 between & 0,03 & 0,06 & 0,11 & 0,06 & 0,03 \\
\hline
\end{tabular}

* coeficiente estadisticamente significativo al $10 \%$

** coeficiente estadisticamente significativo al $5 \%$

*** coeficiente estadisticamente significativo al $1 \%$

económicas, sociales y políticas. Así mismo, los resultados también sugieren que, si bien la tasa de ilegitimidad y la tasa de matrimonios se correlacionan negativamente, existen tanto fuerzas comunes (como los efecto ingreso) como fuerzas que mueven a las variables en direcciones opuestas (como la urbanización).

Nuestros resultados sugieren que el significativo aumento de la tasa de ilegitimidad en el período entre 1880 y 1920 probablemente va asociado a un fuerte proceso de urbanización y de movimientos desde el campo (y de la agricultura) a la ciudad. Este gran aumento en la tasa de ilegitimidad del período mencionado no se compensa por los efectos ingreso hasta la década de los 1920. 
Tabla 6. TASA DE MATRIMONIOS POR CADA 1.000 PERSONAS, ESTIMACIONES A NIVEL DEPARTAMENTAL 1910-1948

\begin{tabular}{|c|c|c|c|c|c|}
\hline \multicolumn{6}{|c|}{ Variable dependiente: Tasa de matrimonios (por 1.000 personas) } \\
\hline & (1) & (2) & (3) & (4) & (5) \\
\hline \multirow[t]{2}{*}{ Razón de hombres a mujeres } & $2,404^{* * *}$ & $3,081^{* * *}$ & $2,728^{* \star *}$ & $2,462^{* * *}$ & $2,213^{* \star *}$ \\
\hline & $(0,706)$ & $(0,766)$ & $(0,776)$ & $(0,778)$ & $(0,795)$ \\
\hline \multirow[t]{2}{*}{ \% población urbana } & $2,439^{* * *}$ & $1,882^{* * *}$ & $1,415^{* *}$ & $2,958^{* *}$ & $2,653^{* * *}$ \\
\hline & $(0,584)$ & $(0,624)$ & $(0,684)$ & $(0,671)$ & $(0,728)$ \\
\hline \multirow[t]{2}{*}{ Log (población) } & & $0,365^{* * *}$ & $0,460^{* * *}$ & $0,648^{* * *}$ & $0,721^{* \star *}$ \\
\hline & & $(0,166)$ & $(0,171)$ & $(0,175)$ & $(0,181)$ \\
\hline \multirow[t]{2}{*}{ Puerto grande } & & & $-0,487$ & & $-0,554$ \\
\hline & & & $(0,597)$ & & $(0,632)$ \\
\hline \multirow[t]{2}{*}{ Puerto chico } & & & $0,797^{\star *}$ & & $0,643^{*}$ \\
\hline & & & $(0,350)$ & & $(0,377)$ \\
\hline \multirow[t]{2}{*}{ \% empleo agrícola } & & & & $-0,914$ & $-0,920$ \\
\hline & & & & $(1,021)$ & $(1,024)$ \\
\hline \multirow[t]{2}{*}{ \% empleo minería } & & & & $-0,870$ & $-0,958$ \\
\hline & & & & $(1,673)$ & $(1,682)$ \\
\hline \multirow[t]{2}{*}{ \% empleo manufactura } & & & & $-5,961^{*}$ & $-5,935^{*}$ \\
\hline & & & & $(3,212)$ & $(3,214)$ \\
\hline Número de observaciones & 609 & 609 & 609 & 425 & 425 \\
\hline Número de departamentos & 62 & 62 & 62 & 62 & 62 \\
\hline $\mathrm{R} 2$ total & 0,27 & 0,27 & 0,28 & 0,34 & 0,35 \\
\hline R2 within & 0,22 & 0,23 & 0,23 & 0,27 & 0,28 \\
\hline R2 between & 0,39 & 0,36 & 0,39 & 0,41 & 0,43 \\
\hline
\end{tabular}

* coeficiente estadisticamente significativo al 10\%

** coeficiente estadisticamente significativo al $5 \%$

${ }^{* \star *}$ coeficiente estadisticamente significativo al $1 \%$

El resultado según el cual la ilegitimidad sería menos intensa en zonas rurales y en departamentos con presencia agrícola fuerte no es consistente con algunas de las hipótesis planteadas por historiadores que plantean que el "huachismo" sería un fenómeno inherentemente relacionado con el campo (Salazar 1990 y 2007). Es interesante también notar que los resultados presentados (que son consistentes con la investigación empírica sobre economía familiar) sugieren que la tasa de ilegitimidad y de matrimonios son fenómenos que cambian frente al contexto existente y a los incentivos que éste genera en el comportamiento de los agentes. 


\section{CONCLUSIONES Y DIRECCIONES DE INVESTIGACIONES FUTURAS}

Este trabajo toma una mirada múltiple para presentar una serie de hechos estilizados sobre la evolución histórica de la tasa de ilegitimidad en Chile. Por una parte, recogemos las hipótesis planteadas en la historiografía nacional como también estudios internacionales sobre el tema, y, por otra, a ellas agregamos las hipótesis planteadas por la literatura económica moderna sobre temas de matrimonio, natalidad y familia. Los resultados más sustantivos apuntan a que la tasa de ilegitimidad y de matrimonios son fenómenos que cambian frente al contexto existente y a los incentivos que ello genera en el comportamiento de los agentes.

En particular, los resultados de este trabajo sugieren que el fuerte aumento de la tasa de ilegitimidad en el período entre 1880 y 1920 probablemente va asociado a un fuerte proceso de urbanización y de movimientos desde el campo (y de la agricultura) a la ciudad. Este gran aumento en la tasa de ilegitimidad del período mencionado no se compensa por los efectos ingreso hasta la década de los 1920. Ciertamente, la contracara de este fenómeno es la tasa de matrimonios por población, donde encontramos que existe una correlación robusta con la razón de hombres a mujeres y con mediciones de desarrollo económico, donde, a más desarrollo, más posibilidades de formalizar la relación de pareja en un matrimonio. Estas conclusiones complementan los resultados de ilegitimidad que discutimos más arriba.

Mirando los datos en una perspectiva de más largo plazo, hay tres conclusiones adicionales que emergen de nuestros análisis. Primero, mientras Chile tuvo tasas de ilegitimidad más altas que muchos países del mundo (e incluso de la región) en el siglo XIX y comienzos del siglo XX, luego conoce un descenso importante hasta mediados de los 1960, que lo pone bajo varios países de la región y muy cerca de países desarrollados. Segundo, el aumento que se observa en Chile a partir de los 1960 también se ve en otros países y probablemente captura cambios culturales más profundos. Y tercero, cuando se mira la historia de Chile, los datos confirman a nivel nacional la información de McCaa (1983) para Petorca de que un porcentaje no menor de la ilegitimidad observada en el pasado corresponde a un fenómeno temporal, pues luego se regularizan los niños y dejan de ser ilegítimos. 
En términos de direcciones de investigaciones a futuro, existen diferentes caminos potenciales a seguir. En primer lugar, nuestro trabajo es el primero que estima un ejercicio econométrico con datos departamentales para el período que va desde 1862 hasta 1948 y sólo identifica correlaciones. Por ello, trabajos que identifiquen relaciones causales, explotando algunos experimentos naturales de la época (quizás relacionados con migración externa, con conflictos bélicos o con shocks de ingreso), pueden generar interesantes avances para entender de mejor manera los resultados encontrados. En segundo lugar, se podría hacer un esfuerzo - no trivial - de recolección de datos a nivel local para períodos anteriores de la historia a fin de avanzar en el estudio de este fenómeno bajo otras circunstancias. Finalmente, también es posible entrar a realizar estudios comparativos entre países, luego de un esfuerzo adicional — nuevamente no trivial— de recolección de datos.

\section{APÉNDICE*}

\section{LEGISLACIÓN SOBRE FILIACIÓN EN CHILE: UNA NOTA BREVE}

La evolución de la legislación chilena sobre filiación puede dividirse en tres etapas: el período previo al dictamen del Código Civil de 1855 , la fase de vigencia de este cuerpo legal en estas materias con sus reformas en el siglo XX y la etapa que comienza en 1998, con la Nueva Ley de Filiación.

En la primera etapa, es decir antes del Código Civil de 1855, las leyes españolas regían en materia de familia, siendo las fuentes relevantes la Novísima Recopilación (1805), el Fuero Real de Alfonso X el Sabio (1255), el Fuero Juzgo (1241) y las Siete Partidas, también de Alfonso X (1265), específicamente la Partida Cuarta que trata de las relaciones de parentesco y familia. También se dictaron algunas leyes especiales entre la Independencia y el dictamen del Código de Bello, como la Ley de Matrimonio de Disidentes (promulgada por Manuel Bulnes en 1844).

* Las siguientes líneas pretenden orientar al lector en los aspectos legales sin pretensión de exhaustividad. Para su elaboración se ha resumido información contenida en Abeliuk (2000), Corral (2005), Rossel (1994) y Somarriva (1983 y 1996). 
Este conjunto de cuerpos normativos no era necesariamente consistente entre sí, pero establecía la distinción entre hijos legítimos (aquellos nacidos en el matrimonio) e ilegítimos. Estos últimos, a su vez, se categorizaban de acuerdo a la situación marital de los padres: hijos naturales (de parejas que podían casarse) y los de dañado y punible ayuntamiento (resultado de uniones ilícitas, incestuosas, adulterinas o sacrílegas).

Además, la norma fijaba los derechos correspondientes a cada tipo de hijo, diferentes estándares de prueba para acreditar su legitimidad. En la práctica, correspondía a un tribunal resolver una demanda por legitimidad.

La segunda etapa corresponde al Código Civil de 1855 (en vigencia desde 1857). Originalmente este código reconocía dos grandes categorías de hijos: legítimos e ilegítimos, siendo los naturales un subgrupo comprendido dentro de esta última categoría. Esencialmente, la normativa establecía como principio que sólo el reconocimiento era capaz de producir el vínculo filial. Los hijos ilegítimos en cuanto tales no gozaban de los mismos derechos que los legítimos en materia de alimentos o derechos sucesorios.

El hijo legítimo era aquel "concebido durante el matrimonio de los padres y el concebido en matrimonio nulo en los casos del artículo 122". Acreditar la legitimidad requería cuatro elementos: la maternidad (que la mujer haya tenido un parto y el hijo que hace pasar por suyo sea realmente el producto de ese parto), el matrimonio (que la madre se encuentra ligada por vínculo matrimonial), concepción dentro del matrimonio (que el matrimonio haya existido al momento de la concepción del hijo, y los hijos nacidos después de 180 días de celebrado el matrimonio se presume que fueron concebidos dentro de éste) y la paternidad (el hijo nacido 180 días después de celebrado el matrimonio se presume que es hijo del marido de la madre, a menos que pueda probarse que el marido no tuvo acceso a su mujer en el rango de tiempo relativo a la concepción).

El hijo legítimo tiene derecho a llevar los apellidos de ambos padres, es legitimario en la herencia de sus padres (asignatario forzoso y en primer lugar), y sus padres tienen deber de crianza y educación, de corrección y castigo. El padre tenía la patria potestad y en caso de faltar aquél, le corresponde dicha facultad a la madre.

Los hijos naturales eran aquellos que no habían nacido al amparo de un vínculo matrimonial pero que eran reconocidos voluntaria y 
espontáneamente por uno o ambos padres (no se podía obligar a los padres a reconocer al hijo como natural). La calidad de hijo natural confería derechos de herencia en conjunto con los hijos legítimos del padre que los tuviere, si bien en menor proporción: sólo la mitad de lo que correspondía a un hijo legítimo.

Respecto de los hijos ilegítimos, se decía en el antiguo artículo 280 inciso primero del Código Civil de 1855: "El hijo ilegítimo que no tenga la calidad de natural sólo tendrá derecho a pedir alimentos del padre o madre, o de ambos, en los casos que enumera el precepto. Son hijos ilegítimos, en consecuencia, aquellos que, nacidos fuera del matrimonio, no han sido reconocidos o no han obtenido el reconocimiento de sus padres como naturales".

Sin embargo, los hijos ilegítimos podían obtener reconocimiento de filiación, pero siempre de manera forzada, a través de tribunales, con el único fin de conseguir alimentos por parte del padre o madre que no lo hubiera reconocido voluntariamente (como "natural"). La filiación ilegítima no daba derechos hereditarios ni derecho a usar el apellido de los padres. En el caso de los alimentos, la regla general es que éstos eran "necesarios" excepto en caso de violación, rapto o estupro de la madre por parte del padre, en cuyo caso se podía demandar alimentos "congruos".

La mayor diferencia entre un hijo natural y un hijo ilegítimo reconocido como tal de manera forzosa se daba en materia de herencias, ya que el hijo natural podía concurrir como heredero legitimario en la herencia de los padres mientras que el ilegítimo no, y únicamente heredaría si así lo disponía el padre o madre, en caso de herencia testada y en la fracción denominada cuarta de libre disposición.

Esta norma experimentó modificaciones desde comienzos del siglo $\mathrm{XX}$, en el sentido de mejorar los derechos de los hijos nacidos fuera del matrimonio. Por una parte, se facilita la investigación de la paternidad por vía judicial, primero para obtener alimentos (Ley n. ${ }^{\circ} 5.570$, de 2 de diciembre de 1935) y luego para lograr la calidad de hijos naturales (Ley n. ${ }^{\circ}$ 10.271, de 2 de abril de 1935). Por otro lado, se incrementan los derechos de los hijos: se suprimen las categorías de hijos de dañado ayuntamiento, permitiendo su acceso a la calidad de hijos naturales (Ley n. ${ }^{0}$ 5.570), se facilita la legitimación por subsiguiente matrimonio que permite el paso de hijo natural a la calidad de legítimo (Ley n. ${ }^{\circ}$ 10.271; Ley n. ${ }^{\circ} 18.802$, de 1989; Ley n. ${ }^{\circ} 19.089$, de 1991), y se incre- 
mentan los derechos alimenticios y los sucesorios de los hijos naturales, aunque en este último caso sin llegar a igualar la porción de los hijos legítimos (Ley n. ${ }^{\circ}$ 10.271).

La tercera etapa en la evolución de la legislación chilena sobre filiación corresponde a la iniciada con la Nueva Ley de Filiación de 1998 (Ley n. ${ }^{\circ}$ 19.585). La principal modificación al Código Civil elimina la diferencia que nuestra legislación establecía respecto a la filiación de los hijos: calificarlos como hijos legítimos, ilegítimos o naturales. Este concepto se ha reemplazado por el de "filiación matrimonial" o "filiación no matrimonial", lo que permite igualar a todos los hijos ante la ley, inclusive en sus derechos hereditarios y al de reclamar alimentos de sus padres.

Todos los nacidos en Chile que no hayan sido reconocidos por sus progenitores tendrán derecho a exigir el reconocimiento de éstos, solicitando la investigación de la supuesta paternidad o maternidad, aportando todo tipo de pruebas para ello, ampliando el espectro a las biológicas, entre ellas, el examen de ADN.

La ley también establece que el derecho de reclamar la filiación es imprescriptible e irrenunciable y que no basta con solicitar la investigación de la paternidad o maternidad ante el Juzgado Civil en que hubiere correspondido interponer la demanda, sino que será el juez el que le dará curso "si con ella se presentan antecedentes suficientes que hagan plausibles los hechos en que se funda".

Respecto a la sucesión por causa de muerte, el viudo o viuda no podrá heredar de su cónyuge una cuota menor a la cuarta parte de la herencia, testada o abintestato, como asimismo se le otorga el derecho de uso y habitación del bien raíz familiar en forma gratuita y por toda la vida, no obstante que existan más herederos que tengan derecho a aquél y quieran venderlo o arrendarlo.

Todos los menores de edad estarán sometidos a la patria potestad de alguno de sus padres. El que la tenga será el representante legal de su hijo, que en el caso de filiación matrimonial la ejerce generalmente el padre, pero, en el caso de existir separación o nulidad matrimonial, la ejercerá el cónyuge que haya obtenido la tuición del menor, casi siempre la madre, de acuerdo a lo establecido en la Ley n. ${ }^{0} 18.802$ ("Ley de la mujer" de 1989), que incorporó al Código Civil fundamentales modificaciones para establecer los derechos de la mujer relativos a los hijos, matrimonio y su plena capacidad, entre otros. 


\section{REFERENCIAS CITADAS}

Abeliuk, René. 2000. La filiación y sus efectos. Santiago: Editorial Jurídica de Chile.

Akerlof, George, Janet Yellen \& Michael Katz. 1996. "An Analysis of Out-ofWedlock Childbearing in the United States". The Quarterly Journal of Economics 111 (2): 277-317.

Bethmann, Dirk \& Michael Kvasnicka. 2013. "World War II, Missing Men and Out of Wedlock Childbearing”. Economic Journal 567: 162-194.

Bladh, Carlos Eduardo. 1951. La República de Chile 1821-1828. Santiago: Imprenta Universitaria.

Borah, Woodrow \& Sherburne Cook. 1966. "Marriage and Legitimacy in Mexican Culture: Mexico and California”. California Law Review 54 (2): 946-1.008.

Brainerd, Elizabeth. 2007. Uncounted Costs of World War II: The Effect of Changing Sex Ratios on Marriage and Fertility of Russian Women. Williamstown: Williams College. http://www.williams.edu/Economics/ faculty/brainerdrfwomen.pdf.

Burguière, André, Christine Klapisch-Zuber, Martine Segalen \& Francoise Zonabend. 1988. Historia de la familia. Madrid: Alianza.

Castro, Teresa, Clara Cortina, Teresa Martin \& Ignacio Pardo. 2011. "Maternidad sin matrimonio en América Latina: Análisis comparativo a partir de datos censales". Notas de Población 93: 37-76.

Cavieres, Eduardo \& René Salinas. 1991. Amor, sexo y matrimonio en Chile tradicional. Valparaíso: Universidad Católica de Valparaíso.

Corral, Hernán. 2005. "La familia en los 150 años del Código Civil chileno". Revista Chilena de Derecho 32 (3): 429-438.

Cuesta, José Ignacio, Francisco Gallego \& Felipe González. 2015. "Local Impacts of Economic Liberalization: Evidence from the Chilean Agricultural Sector". En Economic Policies in Emerging-Market Economies, editado por Ricardo Caballero y Klaus Schmidt-Hebbel, 351-378. Santiago: Banco Central de Chile.

De Guzmán, José. 2011. El chileno instruido en la historia topográfica, civil y política del su país. Santiago: Editorial Universitaria.

Delgado, Manuel. 1986. "Marginación e integración social en Chile. Los expósitos: 1750-1930”. Tesis de grado. Universidad Católica de Valparaíso.

—. 2001. "La infancia abandonada en Chile, 1770-1930". Revista de Historia Social y de las Mentalidades 5: 101-126.

Díaz, José, Rolf Lüders \& Gert Wagner. 2016. Chile, 1810-2010. La república en cifras. Santiago: Ediciones Universidad Católica de Chile (en preparación).

Edlund, Lena. 2013. "The Role of Paternity Presumption and Custodial Rights for Understanding Marriage". Economica 80 (320): 650-669.

Ermisch, John. 2008. "An Economic History of Bastardy in England and Wales". En Quantitative Economic History. The Good of Counting, editado por Joshua Rosenbloom, 8-33. London: Routledge. 
Forero, Andrés, Francisco Gallego, Felipe González \& Matías Tapia. 2015. "Railroads, Specialization, and Population Growth in Chile". Trabajo en progreso, EH Clio Lab, Pontificia Universidad de Chile.

García, Ana. 2004. "Madres solteras, pobres y abandonadas: Ciudad de México, siglo XIX”. Historia Mexicana 53 (3): 647-692.

Goicovic, Igor. 2006. Relaciones de solidaridad y estrategia de reproducción social en la familia popular del Chile tradicional (1750-1863). Madrid: Consejo Superior de Investigaciones Científicas.

Gutiérrez-Domenech, María. 2008. "The Impact of the Labour Market on the Timing of Marriage and Births in Spain". Journal of Population Economics 21 (1): 83-110.

Hartley, Shirley Foster. 1975. Illegitimacy. Berkeley: University of California Press.

Irarrázaval, Ignacio \& Juan Pablo Valenzuela. 1993. "La ilegitimidad en Chile. ¿Hacia un cambio en la conformación de la familia?”. Estudios Públicos 52: 145-190.

Iyigun, Murat \& Jeanne Lafortune. 2015. "Why Wait? A Century of Education, Marriage Timing and Gender Roles". Mimeo.

Johnson, Ann. 1978. "Internal Migration in Chile to 1920: its Relationship to the Labor Market, Agricultural Growth, and Urbanization”. PhD. Thesis. University of California, Davis.

Johnston, Louis \& Samuel Williamson. 2016. "What Was the U.S. GDP Then?". MeasuringWorth. http://www.measuringworth.org/usgdp/.

Kertzer, David \& Marzio Barbagli. 2001. The History of the European Family: Family Life in Early Modern Times (1500-1789). New Haven: Yale University Press.

- 2002. The History of the European Family: Family Life in the Long Nineteenth Century (1789-1913). New Haven: Yale University Press.

- 2003. The History of the European Family: Family Life in the Twentieth Century. New Haven: Yale University Press.

Kirk, Dudley. 1960. "The Influence of Business Cycles on Marriage and Birth Rates". En Demographic and Economic Change in Developed Countries. A Conference of the Universities-National Bureau Committee for Economic Research, editado por Universities-National Bureau, 241-260. New York: NBER.

Kondo, Ayako. 2012. “Gender-specific Labor Market Conditions and Family Formation”. Journal of Population Economics 25 (1): 151-174.

Laslett, Peter \& Karla Oosterveen. 1973. "Long-Term Trends in Bastardy in England. A Study of the Illegitimacy Figures in the Parish Registers and in the Reports of the Registrar General, 1561-1960". Population Studies 27 (2): 255-286.

Laslett, Peter \& Richard Wall. 1972. Household and Family in Past Times. Cambridge: Cambridge University Press. 
Lawton, Richard \& Robert Lee. 2002. Population and Society in Western European Port Cities, 1650-1939. Liverpool: Liverpool University Press.

Mamalakis, Markos. 1978. "Historical Statistics of Chile: An Introduction". Latin American Research Review 13 (2): 127-137.

Martin, Joyce, Brady Hamilton, Michelle Osterman, Sally Curtin \& T. J. Matthews. 2015. "Births: Final Data for 2013". National Vital Statistics Reports 64 (1). http://www.cdc.gov/nchs/data/nvsr/nvsr64/nvsr64_01.pdf.

Martin, Joyce, Brady Hamilton, Stephanie Ventura, Fray Menacker \& Melissa Park. 2002. "Births: Final data for 2000”. National Vital Statistics Reports 50 (5).

Mateo, José. 1996. "Bastardos y concubinas. La ilegitimidad conyugal y filial en la frontera pampeana bonaerense (Lobos 1810-1869)". Boletín del Instituto de Historia Argentina y Americana Dr. Emilio Ravignani 13: 7-33.

McCaa, Robert. 1983. Marriage and Fertility in Chile: Demographic Turning Points in the Petorca Valley, 1840-1976. Boulder: Westview Press.

Mellafe, Rolando \& René Salinas. 1987. Sociedad y población rural en la formación de Chile actual: La Ligua 1700-1850. Santiago: Ediciones de la Universidad de Chile.

Milanich, Nara. 2003. "Perspectiva histórica sobre filiación ilegítima e hijos ilegítimos en América Latina”. Revista de Derechos del Niño 2: 225-249.

- 2009. Children of Fate. Childhood, Class, and the State in Chile, 1850-1930. London: Duke University Press.

Mitchell, Brian. 1988. British Historical Statistics. Cambridge: Cambridge University Press.

Montecino, Sonia. 2010. Madres y huachos. Alegorías del mestizaje chileno. Santiago: Catalonia.

Mooney, Jadwiga. 2009. The Politics of Motherhood. Maternity and Women's Rights in Twentieth-Century Chile. Pittsburgh: University of Pittsburgh Press.

Muñoz, Juan. 1990. "Los hijos naturales en la doctrina de Malloa". En Familia, matrimonio y mestizaje en Chile colonial, editado por Sonia Pinto, 35-50. Santiago: Universidad de Chile.

2005 "Mujeres y vida privada en el Chile colonial". En Historia de la vida privada en Chile, vol. 3, editado por Cristián Gazmuri \& Rafael Sagredo, 95123. Santiago: Taurus.

Neal, Derek. 2004. "The Relationship between Marriage Market Prospects and NeverMarried Motherhood". The Journal of Human Resources 39 (4): 938-957.

Newson, Linda. 2006. "The Demografic Impact of Colonization". En The Cambridge Economic History of Latin America, vol. I, editado por Victor Bulmer-Thomas, John Coatsworth \& Roberto Cortés Conde, 143-184. Cambridge: Cambridge University Press.

Oficina Central de Estadística. 1926. Anuario Estadístico de la República de Chile, vol. I, Demografía, año 1925. Santiago: Soc. Imp. y Lit. Universo.

Ogburn, William \& Dorothy Thomas. 1922. "The Influence of the Business Cycle on Certain Social Conditions". Journal of the American Statistical Association 18: $324-340$. 
Otero, Hernán. 2006. Estadística y nación. Una historia conceptual del pensamiento censal de la Argentina moderna 1869-1914. Buenos Aires: Prometeo Libros.

Pereira, Teresa. 2007. Afectos e intimidades. El mundo familiar en los siglos XVII, XVIII y XIX. Santiago: Ediciones Universidad Católica de Chile.

Ponce de León, Macarena, Francisca Rengifo \& Sol Serrano. 2006. "La 'pequeña república'. La familia en la formación del Estado nacional, 1850-1929”. En El eslabón perdido. Familia, modernización y bienestar en Chile, editado por J. Samuel Valenzuela, Eugenio Tironi \& Timothy Scully, 43-96. Santiago: Taurus.

Retamal, Julio. 2005. "Fidelidad conyugal en el Chile colonial". En Historia de la vida privada en Chile, vol. 1, editado por Cristián Gazmuri \& Rafael Sagredo, 49-69. Santiago: Taurus.

Rojas, Jorge. 2010. Historia de la infancia en el Chile republicano, 1810-2010. Santiago: Junta Nacional de Jardines Infantiles, Junji.

Rossel, Enrique. 1994. Manual de derecho de familia. Santiago: Editorial Jurídica de Chile.

Salazar, Gabriel. 1990. "Ser niño 'huacho' en la historia de Chile (Siglo XIX)". Proposiciones 19: 55-83.

- 2007. Ser niño 'huacho'en la historia de Chile (siglo XIX). Santiago: LOM.

—. 2011. "Reflexiones históricas en torno a las reseñas de Alfredo Jocelyn-Holt y Rolf Lüders sobre el libro Mercaderes, empresarios y capitalistas (Chile, siglo XIX)". Estudios Públicos 129: 263-287.

Salinas, René. 2004. "Historia de la familia chilena". En La familia en Iberoamérica 1550-1980, editado por Pablo Rodríguez, 390-427. Bogotá: Universidad Externado de Colombia.

—. 2005a. "Población, habitación e intimidad en el Chile tradicional". En Historia de la vida privada en Chile, vol. 1, editado por Cristián Gazmuri \& Rafael Sagredo, 11-47. Santiago: Taurus.

_. 2005b. "La pareja: comportamientos, afectos, sentimientos y pasiones". En Historia de la vida privada en Chile, vol. 2, editado por Cristián Gazmuri \& Rafael Sagredo, 59-83. Santiago: Taurus.

—. 2010. "Las otras mujeres: madres solteras, abandonadas y viudas en el Chile tradicional (siglos XVIII-XIX)". En Historia de las mujeres en Chile, vol. 1, editado por Joaquín Fermandois \& Ana María Stuven, 159-212. Santiago: Taurus.

Salinas, René \& Manuel Delgado. 1990. "Los hijos del vicio y del pecado. La mortalidad de los niños abandonados (1750-1830)". Proposiciones 19: 44-54.

San Martín, Benjamín. 1938. "La filiación en su aspecto médico-legal”. Tesis de grado. Universidad de Chile.

Schaller, Jessamyn. 2013. "For Richer, if not for Poorer? Marriage and Divorce over the Business Cycle". Journal of Population Economics 26 (3): 1.0071.033 . 
Schelleckens, Jona. 1995. "Courtship, the Clandestine Marriage Act, and Illegitimate Fertility in England". Journal of Interdisciplinary History 25 (3): 433-444.

Servicio Nacional de Estadística y Censos. 1951. Demografia y asistencia social, año 1951. Santiago: Servicio Nacional de Estadística y Censos.

Somarriva, Manuel. 1983. Derecho de familia, vol. 2. Santiago: Ediar Editores.

— 1996. Derecho sucesorio, vol. 1. Santiago: Editorial Jurídica de Chile.

Strouffer, Samuel \& Lyle Spencer. 1936. "Marriage and Divorce in Recent Years". The Annals of the American Academy of Political and Social Science 188: 5669.

Twinam, Ann. 1999. Public Lives, Private Secrets. Gender, Honor, Sexuality, and Illegitimacy in Colonial Spanish America. Stanford: Stanford University Press.

USBC. 2012. The 2012 Statistical Abstract: Historical Statistics. https://www. census.gov/compendia/statab/hist_stats.html.

Valdés, Ximena. 2004. "Familias en Chile: rasgos históricos y significados actuales de los cambios". En Cambio de las familias en el marco de las transformaciones globales: necesidad de politicas públicas eficaces, compilado por Irma Arriagada \& Verónica Aranda, 333-351. Santiago: División de Desarrollo Social, Cepal.

Vargas, Nelson. 2002. Historia de la pediatría chilena: Crónica de una alegría. Santiago: Editorial Universitaria.

Ventura, Stephanie \& Christine Bachrach. 2000. "Nonmarital Childbearing in the United States, 1940-99”. National Vital Statistics Reports 48 (16).

Wall, Richard, Tamara Hareven \& Josef Ehmer. 2001. Family History Revisited: Comparative Perspectives. Newark. Delaware: University of Delaware Press.

Willis, Robert. 1999. "A Theory of Out-of-Wedlock Childbearing”. Journal of Political Economy 107 (s6): 33-64.

Wilson, William. 1987. The Truly Disadvantaged: The Inner City, the Underclass, and Public Policy. Chicago: University of Chicago Press.

Zárate, María Soledad. 2007. Dar a luz en Chile, siglo XIX. De la "ciencia de hembra" a la ciencia obstétrica. Santiago: Dibam. EP 